OPEN ACCESS

Edited by:

Qi Yuan,

Memorial University of Newfoundland,

Canada

Reviewed by: Claire Cheetham,

Carnegie Mellon University, USA Hongbing Wang,

Michigan State University, USA

${ }^{*}$ Correspondence:

Zhenshan Wang

zswang@hbu.edu.cn

tThese authors have contributed equally to this work.

Received: 17 October 2016 Accepted: 04 January 2017 Published: 19 January 2017

Citation:

Zhang Z, Yang D, Zhang $M$, Zhu N, Zhou $Y$, Storm DR and Wang $Z$ (2017) Deletion of Type 3 Adenylyl Cyclase Perturbs the Postnatal Maturation of Olfactory Sensory Neurons and Olfactory Cilium

Ultrastructure in Mice.

Front. Cell. Neurosci. 11:1 doi: 10.3389/fncel.2017.00001

\section{Deletion of Type 3 Adenylyl Cyclase Perturbs the Postnatal Maturation of Olfactory Sensory Neurons and Olfactory Cilium Ultrastructure in Mice}

Zhe Zhang ${ }^{1,2 t}$, Dong Yang ${ }^{1 t}$, Mengdi Zhang ${ }^{1}$, Ning Zhu ${ }^{3}$, Yanfen Zhou ${ }^{1}$, Daniel R. Storm ${ }^{4}$ and Zhenshan Wang ${ }^{1 *}$

${ }^{1}$ College of Life Science, Hebei University, Baoding, China, ${ }^{2}$ Medical College, Hebei University, Baoding, China, ${ }^{3}$ Department of Cardiology, Baoding First Center Hospital, Baoding, China, ${ }^{4}$ Department of Pharmacology, University of Washington, Seattle, WA, USA

Type 3 adenylyl cyclase (Adcy3) is localized to the cilia of olfactory sensory neurons (OSNs) and is an essential component of the olfactory cyclic adenosine monophosphate (CAMP) signaling pathway. Although the role of this enzyme in odor detection and axonal projection in OSNs was previously characterized, researchers will still have to determine its function in the maturation of postnatal OSNs and olfactory cilium ultrastructure. Previous studies on newborns showed that the anatomic structure of the main olfactory epithelium (MOE) of $A d c y 3$ knockout mice $\left(A d c y 3^{-/-}\right.$) is indistinguishable from that of their wild-type littermates $\left(A d c y 3^{+/+}\right)$, whereas the architecture and associated composition of MOE are relatively underdeveloped at this early age. The full effects of sensory deprivation on OSNs may not also be exhibited in such age. In the present study, following a comparison of postnatal OSNs in seven-, 30-, and 90-day-old Adcy3-/- mice and wild-type controls (Adcy $3^{+/+}$), we observed that the absence of Adcy3 leads to cumulative defects in the maturation of OSNs. Upon aging, Adcy $3^{-1-}$ OSNs exhibited increase in immature cells and reduction in mature cells along with elevated apoptosis levels. The density and ultrastructure of $A d c y 3^{-/-}$cilia were also disrupted in mice upon aging. Collectively, our results reveal an indispensable role of Adcy3 in postnatal maturation of OSNs and maintenance of olfactory cilium ultrastructure in mice through adulthood.

Keywords: olfactory sensory neurons, type 3 adenylyl cyclase, olfactory cilia, main olfactory epithelium, apoptosis

\section{INTRODUCTION}

The main olfactory epithelium (MOE) is a pseudostratified epithelial structure required for odor perception in mammals (Beites et al., 2005). The neural stem cells located in the basal epithelium give rise to olfactory sensory neurons (OSNs) (Jang et al., 2014). Several million OSNs, consisting of immature olfactory sensory neurons (iOSNs) and mature olfactory sensory neurons (mOSNs), are situated in the middle of the MOE. mOSNs are equipped with cilia, in which the olfactory cyclic adenosine monophosphate (cAMP) signaling cascade members, which are critical for proper 
olfactory function, are enriched (Menco, 1997; Heron et al., 2013). One unique characteristic of OSNs is their continuous neurogenesis that occurs throughout life. OSNs undergo caspasemediated apoptosis at all stages of their life cycle (Mahalik, 1996). These cells are subsequently replenished by newly generated OSNs from the division of the basal stem cells to maintain epithelial homeostasis.

The equilibrium between OSN survival and apoptosis is possibly regulated by odorant-stimulated neural activity and sensory experience (Zhao et al., 2013; Cadiou et al., 2014; Kikuta et al., 2015). Sensory input plays a critical role in the survival of OSNs during postnatal MOE development (Farbman et al., 1988; Stahl et al., 1990; Brunjes, 1994; Coppola et al., 2006). Olfactory sensory deprivation in neonatal mice using unilateral naris occlusion results in a thinner MOE, fewer OSNs, and reduced number of olfactory marker protein (OMP)-positive cells (Coppola et al., 2006; Coppola, 2012).

The lifespan of OSNs was observed to be significantly longer in $H 2 B E$ (an olfactory-specific histone variant) knockouts and shorter in H2BE-overexpressing mice (Santoro and Dulac, 2012). cAMP mediated the activity-dependent downregulation of $\mathrm{H} 2 \mathrm{BE}$ (Santoro and Dulac, 2012). In addition, the activity-dependent survival of OSNs was promoted by cAMP pathway-dependent MAPK activation (Watt et al., 2004), implying that olfactory cAMP signaling might be required for the survival of OSNs in mice.

Interestingly, studies showed that the gross and microscopic anatomy of MOE in cAMP-signaling-cascade-member-knockout mice, including type 3 adenylyl cyclase (Adcy3), G-proteinolfactory-subunit $\left(G_{\text {olf }}\right)$, and cyclic-nucleotide-gated-channel $\alpha$ subunit $(C N G \alpha)$ knockouts, were indistinguishable from their wild-type littermates (Brunet et al., 1996; Belluscio et al., 1998; Wong et al., 2000). The similar appearance raised the possibility that odorant detection and stimulation-mediated OSN survival might be processed via independent signaling pathways (Kim et al., 2015). However, a limitation of these studies involved using 1-day-old pups as cAMP-cascade-component knockout mice. At this early age, architecture and associated composition of MOE are relatively underdeveloped. Accordingly, the full effects of sensory deprivation on maturation of OSNs may not be exhibited. For example, the MOE of OMP- $d n R A R$ knockout and littermate control mice were indistinguishable in relation to cellular organization, thickness, and OMP immunoreactivity at postnatal day (P) 1, whereas both thickness of the MOE and OMP immunoreactivity were reduced in transgenic mice compared with littermates after 1 month (Hagglund et al., 2006). Moreover, cilium density and morphology were normal before P5 in Centrin2 (CETN2) knockout mice, whereas increased cilia loss was exhibited in P14 (and older) CETN2 mutant MOE (Ying et al., 2014). The OSNs of $A d c y 3^{-/-}$mice are devoid of odorant-evoked activity at both behavioral and electrophysiological levels (Wong et al., 2000). In addition, Adcy3 expression in the OSNs of postnatal animals are both age- and location-dependent (Zou et al., 2007; Challis et al., 2015; Login et al., 2015), and the time of $A d c y 3$ expression significantly influences the behavior of OSN axons (Rodriguez-Gil et al., 2015). Accordingly, the absence of sensory input in $A d c y 3^{-/-}$mice may lead to developmental impairment of postnatal OSNs upon aging.

In this study, we examined the OSNs of $A d c y 3^{-/-}$mice and $A d c y 3^{+/+}$littermates after seven, 30, and 90 postnatal days and demonstrated that the absence of Adcy3 induced the formation of thinner MOE and increased loss of mOSNs along with elevated levels of apoptosis. Additionally, cilium density and ultrastructure were also severely disrupted in OSNs of $A d c y 3^{-/-}$ MOE.

\section{MATERIALS AND METHODS}

\section{Mice}

Adcy $3^{+/-}$mice were obtained from the Storm Laboratory, University of Washington, Seattle, United States. Adcy $3^{+/+}$and Adcy $3^{-/-}$mice were bred from heterozygotes and genotyped using polymerase chain reaction (PCR), as previously described (Wang and Storm, 2006). All mice were housed under a $12 \mathrm{~h}$ light/dark cycle and provided with access to food and water ad libitum in a specific pathogen-free animal room in Hebei University. All experimental procedures were performed under the Guiding Opinions on the Treatment of Experimental Animals issued by the Ministry of Science and Technology, People's Republic of China and approved by the Animal Ethics and Caring Committee of Hebei University.

\section{RNA Isolation and Quantitative Real-Time PCR}

Main olfactory epitheliums from $A d c y 3^{+/+}(n=3)$ and Adcy3 $3^{-/-}(n=3)$ mice at P7, P30, and P90 were dissected. RNA of MOE was isolated using traditional TRIzol method (Ambion, cat. nos. 208054). cDNA was synthesized using PrimeScript $^{\mathrm{TM}}$ RT Reagent Kit with gDNA Eraser (TaKaRa, cat. nos. RR047A). Quantitative Adcy3 expression was determined through three-step quantitative reverse transcription polymerase chain reaction (qRT-PCR) using QuantiNava ${ }^{\text {TM }}$ SYBR Green PCR Kit (QIAGEN, cat. nos. 208054) (sequences of Adcy3 primers are as follows: Adcy3 F, AGATGTTCGGTGCCACCTG; Adcy3 R, ACTTCACCAGGGCTTCGTAAG). Adcy3 mRNA expression was determined using the $2^{-\Delta \Delta C T}$ method (Livak and Schmittgen, 2001) and normalized to that of the housekeeping gene, $\beta$-actin [sequences of $\beta$-actin primers are as follows: $\beta$-actin F, CTAAGGCCAACCGTGAAAAG; $\beta$-actin R, ACCAGAGGCATACAGGGACA (Sciacovelli et al., 2016)].

\section{Processing of Samples and Tissue Sections for Light Microscopy}

Mice were anesthetized with intraperitoneal injection of pentobarbital sodium (100 mg/kg body weight). Animals were transcardially perfused with $0.9 \%$ physiological saline followed by $4 \%$ paraformaldehyde ( $\mathrm{PFA}, \mathrm{pH} 7.4$ ). The nasal cavity was postfixed overnight in $4 \% \mathrm{PFA}$ at $4^{\circ} \mathrm{C}$ and was subsequently transferred into 10,20 , and $30 \%$ sucrose in phosphate-buffered saline (PBS) until sinking (older mice were decalcified in 1

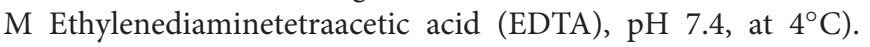


Postfixed specimens were then embedded under optimal cutting temperature. The olfactory tissue was coronally sectioned using a freezing microtome (Leica 1950). The sections were used for either hematoxylin-eosin (HE) staining or immunofluorescence staining procedures.

\section{Scanning Electron Microscopy (SEM)}

For SEM observations, $A d c y 3^{-/-}$and $A d c y 3^{+/+}$male mice ( $n=3$ each) aged P7, P30, and P90 were transcardially perfused with $2.5 \%$ glutaraldehyde (in $0.1 \mathrm{M}$ phosphate buffer, $\mathrm{pH} 7.4$ ). After fixation, the heads were hemisected, the nasal cavity was exposed under a dissecting microscope, and olfactory mucosa was removed from the dorsal zone along the medial aspect (where robust location-dependent change in cilium length was observed) and further fixed overnight in $2.5 \%$ glutaraldehyde at $4^{\circ} \mathrm{C}$. The samples were washed four times with $0.1 \mathrm{M}$ phosphate buffer ( $\mathrm{pH}$ 7.4), dehydrated in increasing ethanol concentrations (50, $70,80,90$, and $100 \%$ ), and dried using a vacuum pump. The dried samples were then coated with gold particles (EIKO IB-3) and examined using the scanning microscope (Hitachi S-3500N) at $20 \mathrm{KV}$.

\section{Transmission Electron Microscopy (TEM)}

For TEM observations, similar regions of the olfactory mucosa observed via SEM were examined using TEM in both $A d c y 3^{-/-}$ and $A d c y 3^{+/+}$male mice $(n=3$ each). The olfactory mucosa from mice aged P30 and P90 was fixed for $4 \mathrm{~h}$ in $4 \%$ glutaraldehyde (in $0.1 \mathrm{M}$ phosphate buffer, $\mathrm{pH} 7.4$ ) at $4^{\circ} \mathrm{C}$. The samples were washed and postfixed for $2 \mathrm{~h}$ in $1 \%$ osmium tetroxide $(\mathrm{pH} 7.4)$ at $4^{\circ} \mathrm{C}$. Washed specimens were dehydrated in increasing ethanol concentrations (50, 70, 80, 90, and 100\%). The specimens were then dried in propylene oxide and infiltrated overnight with an Epon resin mix/propylene oxide (1:1) mixture. This step was followed by infiltration with $100 \%$ Epon resin for $48 \mathrm{~h}$. The specimens were embedded and cured in plastic following incubation in an oven at $60^{\circ} \mathrm{C}$ for $48 \mathrm{~h}$. The sections (thickness $=1 \mu \mathrm{m}$ ) were cut using an ultramicrotome (Lecia UC7) until the desired region was reached. Ultrathin sections (50 $\mathrm{nm}$ thick) were then prepared, stained with uranyl acetate and lead citrate, and examined using TEM (Hitachi H-7000).

\section{Immunofluorescence}

Immunofluorescence staining of tissue sections was performed according to a previously published protocol (Wang et al., 2011). The sections were rinsed with PBS ( $\mathrm{pH} 7.4$ ) and incubated in a blocking solution (containing 10\% serum, 5\% BSA, and $0.2 \%$ Tritonx-100) for $1 \mathrm{~h}$ at $37^{\circ} \mathrm{C}$. The sections were then incubated with the following primary antibodies at $4^{\circ} \mathrm{C}$ overnight: goat anti-OMP (1:500; Wako, cat. nos. 019-22291), rabbit antigrowth associated protein-43 (GAP43) (1:500; Millipore, cat. nos. AB5220), mouse anti-acetylated (Ac)- $\alpha$-tubulin (1:1000; SigmaAldrich, cat. nos. T6199), rabbit anti-cleaved caspase3 (1:200; cell signaling, cat. nos. 9661S), mouse anti-bromodeoxyuridine (BrdU, 1:200; Sigma-Aldrich, cat. nos. B5002), mouse antiKi67 (1:300; BD, cat. nos. 556003), and mouse anti-Mash1 (1:150; BD, cat. nos. AF796). After washing thrice with Phosphate Buffer Solution +Tween-20 (PBST), sections were incubated with reciprocal Alexa Fluor dye-conjugated secondary antibodies (1:500, Invitrogen) for $1 \mathrm{~h}$ at room temperature. The signal in Ki67 and Mash1-staining was amplified by the deposition of fluorescein using the TSA Fluorescein System (1:50; PerkinElmer Life, cat. nos. NEL701A001KT). The sections were counterstained with 4'6-diamidino-2-phenylindole (DAPI) (2 $\mu \mathrm{g} / \mathrm{mL}$; Sigma, cat. nos. D9542) and coverslipped with PBS, which instead of being used as primary antibody, was used in negative controls.

\section{BrdU Injections}

To examine cell proliferations in MOE, male mice $(n=3$ each group) aged P7 and P30 were intraperitoneally injected with BrdU (Sigma-Aldrich, cat. nos. B8434) (100 mg/kg body weight, dissolved in sterile saline) $2 \mathrm{~h}$ prior to perfusion. Male mice ( $n=3$ each group) aged P7, P30, and P90 were also injected thrice intraperitoneally (100 $\mathrm{mg} / \mathrm{kg}$ body weight) (with intervals of $2 \mathrm{~h}$ ) for three consecutive days. Mice were perfused 4 weeks later, and lifespan of neurons in the MOE was examined. PFA-fixed sections were incubated with $2 \mathrm{~N} \mathrm{HCl}$ for $30 \mathrm{~min}$ at $37^{\circ} \mathrm{C}$ before immunostaining with anti-BrdU antibody. The subsequent immunostaining procedure was identical to that used for other antibodies.

\section{Imaging and Quantitative Analysis}

HE-stained sections were examined and photographed using $\times 40$ lens $(\mathrm{NA}, 0.95)$ of an Olympus BX53 under bright-field illumination. Immunofluorescence-stained sections were imaged using Olympus IX81 FLUOVIEW confocal microscope. Z-stack images $(1024 \times 1024$ pixels $)$ were captured using $\times 20(\mathrm{NA}, 0.75)$ and $\times 40(\mathrm{NA}, 0.95)$ objective lenses. In these image stacks, all labeled cells were counted, and we simultaneously determined whether these cells were doublelabeled for OMP and caspase3. All images were only processed to facilitate contrast, brightness, and color-balance optimization using Adobe Photoshop CS software.

The thickness of MOE in HE sections, defined as the length from the basement membrane to the top of the knobs, was measured as documented in literature (Weiler and Farbman, 1997; Barrios et al., 2014). The same threshold was applied for all images obtained from the experiment. Laser intensity and detector gain were individually adjusted for each filter for maximum dynamic range, and settings were left unchanged for all the images collected in a section. In addition, no other attempts were made to normalize measurements background immunostaining. The background is a random factor, which is unrelated to the genotypes or treatments. Therefore, this measurement should lead to more conservative inferences. Positive cells under higher magnification images $(40 \times$ objective) were manually counted using the "Cell Counter" tool of ImageJ plugins. For all quantifications, the experimenter was blinded to genotypes of the studied animals. The epithelial length along olfactory mucosa was measured using AxioVision software. Cell density was calculated by dividing the number of immunopositive cells by epithelial length (cells number/mm) for each age group. The number of immunopositive cells was finally converted based 
on the method published by Abercrombie (1946): corrected number $=$ count $\times$ [section thickness $/($ section thickness + mean nucleus size)] (Abercrombie, 1946).

\section{Statistical Analysis}

All data were expressed as mean \pm standard error, unless otherwise indicated. Statistical analyses were performed with SPSS 21.0. Normality of distribution of variables and homogeneity of variances were checked through Shapiro-Wilk's and Levene's tests, respectively. We analyzed the data using one- or two-way ANOVA with post hoc pairwise comparisons. $p<0.05$ was considered statistically significant.

\section{RESULTS}

\section{Deletion of Adcy3 Reduces Cell Number and Thickness of the MOE}

By using qRT-PCR analysis, we confirmed that the Adcy3 expression levels in MOEs of P7, P30, and P90 Adcy3 ${ }^{-/}$mice are significantly lower compared with those of $A d c y 3^{+/+}$mice with the same ages (Figure 1I). To evaluate whether the overall structure of the MOE is affected by Adcy3 deletion, we performed HE staining on specimens from P7, P30, and P90 Adcy3 $3^{+/+}$and $A d c y 3^{-/-}$mice. Our analyses were restricted to the mid-dorsal mucosa in each specimen to avoid morphological variations in the analyzed regions. The restriction was based on different regions of the MOE with different thicknesses. In general, the dorsal regions are thicker than the corresponding ventral regions, the medial regions are thicker than the lateral regions, and the middle and posterior regions are thicker than the anterior areas (Barrios et al., 2014).

In wild-type mice, results showed that the MOE at P7 was relatively thicker than those at P30 and P90, and the cells were loosely arranged (Figure 1A). Upon adulthood, the MOE became thinner, and neurons were more densely arranged (Figures 1B,C). These observations were consistent with those of previous histological studies, which showed the age-dependent decrease in epithelial thickness of murine MOE (Kondo et al., 2010). In Adcy3 ${ }^{-/-}$mice, the MOE

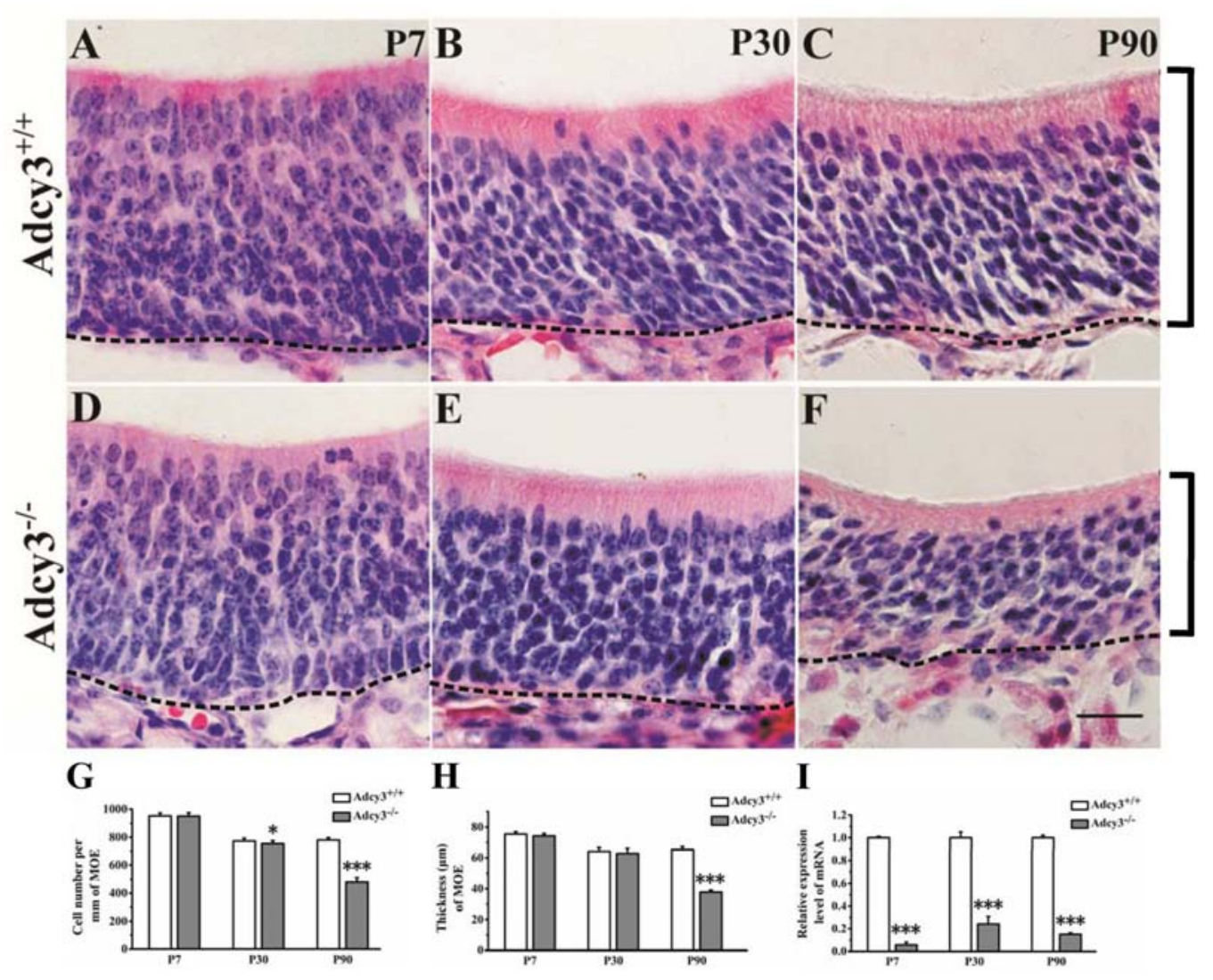

FIGURE 1 | Cell number and thickness of the MOE decreased in P90 Adcy $\mathbf{3}^{-/-}$mice. (A-C) Representative images of HE-stained sections of the MOE at P7 (A), P30 (B), and P90 (C) Adcy3 ${ }^{+/+}$mice. (D-F) Representative images of HE-stained sections from Adcy3-/- mice at P7 (D), P30 (E), and P90 (F). Cells were irregularly arranged in P90 Adcy3 $3^{-/-}$mice (F). (G) Quantitative analysis of cell density of MOE, showing a slight reduction at P30 and substantial decrease in P90 Adcy3 ${ }^{-/-}$mice compared with that of $A d c y 3^{+/+}$controls. (H) Quantitative analysis of MOE thickness, showing a substantial decrease in P90 Adcy3-/- mice compared with of $A d c y 3^{+/+}$controls. (I) Relative Adcy3 mRNA expression levels in MOEs of P7, P30, and P90 mice. Adcy3 expression level significantly decreased in $A d c y 3^{-/-}$mice compared with that of $A d c y 3^{+/+}$controls at all ages examined. Black brackets indicate thickness of MOE. Data are presented as mean \pm standard error; $n=3$ for each group; ${ }^{*} P<0.05$, ${ }^{* * *} P<0.001$. Scale bars: (A-F), $20 \mu \mathrm{m}$. 
cell density varied little from that of wild-type mice at P7 $\left(\right.$ Adcy3 ${ }^{-/-}, 949.36 \pm 24.19 / \mathrm{mm} ;$ Adcy3 $3^{+/+}, 951.07 \pm 21.21 / \mathrm{mm}$; $p=0.858$; Figures $\mathbf{1 A}, \mathbf{D}, \mathbf{G})$ and the MOE cell density at P30 was slightly reduced when compared with that of $A d c y 3^{+/+}$mice (Figures 1E,G). However, in P90 Adcy $3^{-/-}$mice, the cell density of MOE sharply decreased (Adcy3 $3^{-/-}, 479.92 \pm 31.67 / \mathrm{mm}$; Adcy $3^{+/+}, 780.11 \pm 17.05 / \mathrm{mm} ; p=0.000$; Figures 1C,F,G), and the MOE was much thinner $\left(\right.$ Adcy $3^{-/-}, 37.79 \pm 1.34 \mu \mathrm{m}$; Adcy $3^{+/+}, 65.16 \pm 1.95 \mu \mathrm{m} ; p=0.000$; Figures 1C,F,H) when compared with wild-type specimens. Compared with the cell density of $A d c y 3^{+/+}$mice at P90, the cell density of MOE in $A d c y 3^{-/-}$mice was $38.5 \%$ less at the same period of observation (Figure 1G). Together, these data suggest that Adcy3 deletion results in the gradual decline in cell number after birth and profound reduction in adult mice. The complete structure of the MOE is apparently affected by Adcy3 loss as animals age reach adulthood after the postnatal stages.

\section{Deletion of Adcy3 Increases iOSN and Reduces mOSNs}

To further characterize OSN maturation in Adcy3-/mice, we examined the expressions of the immature OSN marker, GAP43, and the mature OSN marker, OMP, in the MOE. In $A d c y 3^{+/+}$mice, the number of $\mathrm{GAP}_{4}{ }^{+}$ cells decreased from age P7 (589.25 $\pm 13.60 / \mathrm{mm})$ and P30 (222.55 $\pm 20.10 / \mathrm{mm})$ until P90 (157.49 $\pm 26.91 / \mathrm{mm})$ (Figures 2A,C,E,H). Concurrently, an increase in $\mathrm{OMP}^{+}$ cells was observed following $\mathrm{MOE}$ development from age P7 and P30 until P90 (Figures 2A,C,E,G). By contrast, the Adcy $3^{-/-}$MOE exhibited a higher number of $\mathrm{GAP} 43^{+}$cells and significantly reduced $\mathrm{OMP}^{+}$cells at all postnatal ages examined (Figures 2B,D,F,G,H). GAP43 expression was apically increased $\left(A d c y 3^{-/-}, 319.23 \pm 21.69 / \mathrm{mm} ; A d c y 3^{+/+}\right.$, $157.49 \pm 26.91 / \mathrm{mm} ; p=0.000$ ) (Figures 2E,F,H), mOSN layer was reduced and mainly restricted to the most apical layer of the MOE, below the supporting cells in the MOEs of P90 Adcy $3^{-/-}$mice $\left(A d c y 3^{-/-}, 134.38 \pm 17.79 / \mathrm{mm} ; A d c y 3^{+/+}\right.$, $501.59 \pm 28.43 / \mathrm{mm} ; p=0.000$; Figures $2 E, F, G)$. Remarkably, the number of $\mathrm{OMP}^{+}$cells in $\mathrm{P} 90 \mathrm{Adcy3}^{-/-}$mice was much less than that observed in P30 Adcy3 $3^{-/-}$mice (P30, $213.46 \pm 35.52 / \mathrm{mm}$; P90, $134.38 \pm 17.79 / \mathrm{mm} ; p=0.000$; Figures $2 D, F, G)$, which is obviously not consistent with normal OSN development patterns exhibited in $A d c y 3^{+/+}$mice. Although the total OSN number $\left(\mathrm{OMP}^{+}\right.$and $\mathrm{GAP}_{4}{ }^{+}$) between $A d c y 3^{+/+}$and $A d c y 3^{-/-}$mice varied little at P7 and P30, it significantly decreased in Adcy3 $3^{-/-}$ mice at P90 (Figure 2I). Together, these data demonstrate that $A d c y 3$ deletion reduces mOSN number and inhibits OSN development at the immature neuronal stage of mice during adulthood.

\section{Deletion of Adcy3 Reduces the Lifespan of OSNs}

One hypothesis regarding the reduced cell numbers in the OSNs is that this phenomenon arises from reduction in cell lifespan, increase in apoptotic cell number, and/or decreased proliferation of progenitors. To test this possibility, we utilized long-term BrdU incorporation analysis to measure the OSN lifespan. Adcy3-/mice and wild-type littermates were injected with BrdU at ages P7, P30, and P90. Mice were subsequently sacrificed 4 weeks after injection. The number of $\mathrm{BrdU}^{+}$cells in $A d c y 3^{-/-}$mice significantly decreased relative to $A d c y 3^{+/+}$controls at each of the examined stage (Figures $\mathbf{3 A - G}$ ). These data indicate that Adcy3 deletion shortens the lifespan of OSNs.

\section{Adcy3 Deletion Does Not Suppress Cell Proliferation in MOE}

To assess whether reduction of OSNs in $A d c y 3^{-/-}$mice resulted from alterations to cell proliferation mechanisms, we analyzed the expression of the neuronal progenitor marker, Mash1, a marker for globose basal cells (GBCs). Mash1 expression did not differ between $A d c y 3^{-/-}$and $A d c y 3^{+/+}$mice at P7 and P30 (Figures 4A-E), indicating that OSN progenitors are possibly not affected by the loss of Adcy3 and develop normally into neurons at the early stages of neurogenesis. We identified actively proliferating cells using two markers, BrdU and Ki67, which are both used as labels for multiplying cells. Animals were injected with a single dose of BrdU and perfused after $2 \mathrm{~h}$. The MOE sections were immunolabeled with antibodies against BrdU and Ki67. At P7, $A d c y 3^{+/+}$and $A d c y 3^{-/-}$MOE showed a substantial number of BrdU-labeled proliferating cells (Figures 4F,G). $\mathrm{BrdU}^{+}$cells were predominantly scattered near the basal neuroepithelium at both genotypes of P30 mice (Figures 4H,I). Furthermore, $\mathrm{BrdU}^{+}$cell numbers also decreased with aging in $A d c y 3^{+/+}$and $A d c y 3^{-/-}$mice (Figure 4J). However, significant difference was not observed between $A d c y 3^{+/+}$and $A d c y 3^{-/-}$ mice at P7 and P30 in terms of $\mathrm{BrdU}^{+}$cell numbers (Figure 4J). $\mathrm{Ki}^{+}{ }^{+}$cells were expressed in both the basal and apical layers of MOEs in the $A d c y 3^{+/+}$and $A d c y 3^{-/-}$mice at P7 (Figures 4 $\mathbf{K}, \mathbf{L})$, and were mainly restricted to the basal layer at P30 (Figures 4M,N). Compared with $\mathrm{P} 7$ mice, the $\mathrm{Ki}^{+} 7^{+}$cells decreased at P30 in both $A d c y 3^{+/+}$and Adcy3 ${ }^{-/-}$MOEs (Figure 4O). Similarly, the number of $\mathrm{Ki}^{+} 7^{+}$proliferating cells varied minimally between $A d c y 3^{-/-}$and $A d c y 3^{+/+}$mice at P7 and P30 (Figure 40). Together, these data indicate that Adcy3 deletion does not suppress cell proliferation in MOE.

\section{Deletion of Adcy3 Increases Apoptotic Cell Number of mOSNs}

To determine whether the decrease in OSN in $A d c y 3^{-/-}$MOE resulted from an overall increase in postnatal apoptosis, we tested for the expression of cleaved-caspase3, an enzyme critically involved in mammalian apoptotic pathway. Compared with P7 Adcy $3^{+/+}$MOE, the number of caspase $3^{+}$cells decreased at P30 and P90 (Figure 5G). Only relatively few apoptotic cells were observed in the basal layer of MOE at P30 and P90 Adcy $3^{+/+}$mice (Figures 5B,C,G). The number of caspase $3^{+}$cells differed minutely between $A d c y 3^{-/-}$and $A d c y 3^{+/+}$mice at P7 (Figures 5A,D,G). However, we observed a significant increase in the number of caspase $3^{+}$cells in P30 and P90 Adcy3 ${ }^{-/-}$mice compared with their $A d c y 3^{+/+}$controls (Figures 5B,C,E,F,G). The number of apoptotic cells in P90 Adcy3 $3^{-/-}$mice was approximately 10-fold higher than that observed for $A d c y 3^{+/+}$ 

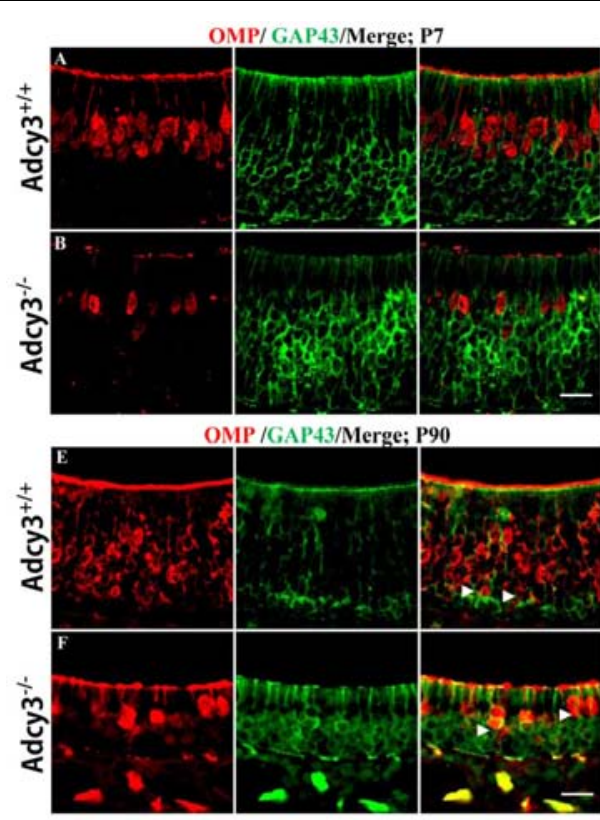

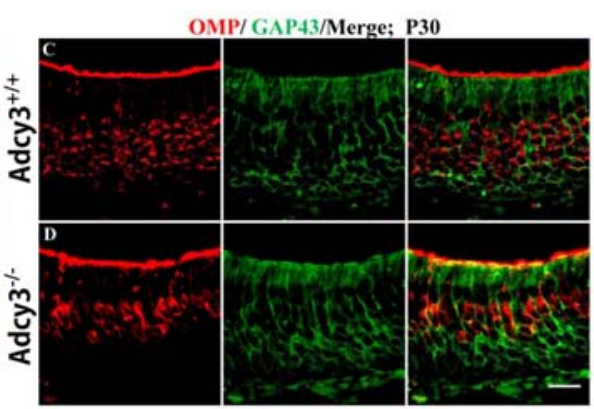

H

G
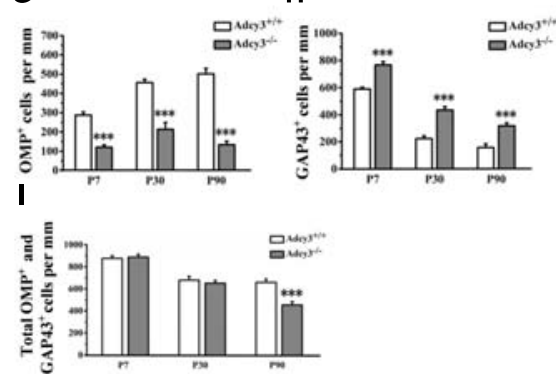

FIGURE 2 | Expression of OMP and GAP43 is altered in the MOE of $A d c y 3^{-/-}$mice. (A-F) Representative images of MOE sections stained with OMP and GAP43 (green) in $A d c y 3^{+/+}$(top) and $A d c y 3^{-/-}$(lower) mice at P7 (A,B), P30 (C,D), and P90 (E,F). In Adcy3 $3^{+/+}$mice at ages from P7, P30, to P90, a reduction in $\mathrm{GAP}_{4} 3^{+}$cells and an increase in $\mathrm{OMP}^{+}$cells were observed (A,C,E). A distinct boundary was noted between $\mathrm{OMP}^{+}$mOSN and GAP43 ${ }^{+} \mathrm{iOSN}$ in P90 Adcy3 ${ }^{+/+}$ mice (E, arrowheads). GAP43 expression was more elevated in $A d c y 3^{-/-}$mice compared with that of $A d c y 3^{+/+}$controls, whereas OMP expression was substantially reduced (B,D,F). The boundary between OMP and GAP43 was obscured in P90 Adcy3 ${ }^{-/-}$mice (F, arrowheads). (G,H) Quantitative analysis of OMP ${ }^{+}$ and GAP $43^{+}$cell numbers in $A d c y 3^{+/+}$and $A d c y 3^{-/-}$mice at all ages examined. (I) Quantitative analysis of the total $\mathrm{OMP}^{+}$and $\mathrm{GAP} 43^{+}$cells in $\mathrm{Adcy} 3^{+/+}$and Adcy $3^{-/-}$mice at all ages examined. Data are presented as mean \pm standard error; $n=3$ for each group; ${ }^{* * *} P<0.001$. Scale bars: (A-F), $20 \mu \mathrm{m}$.
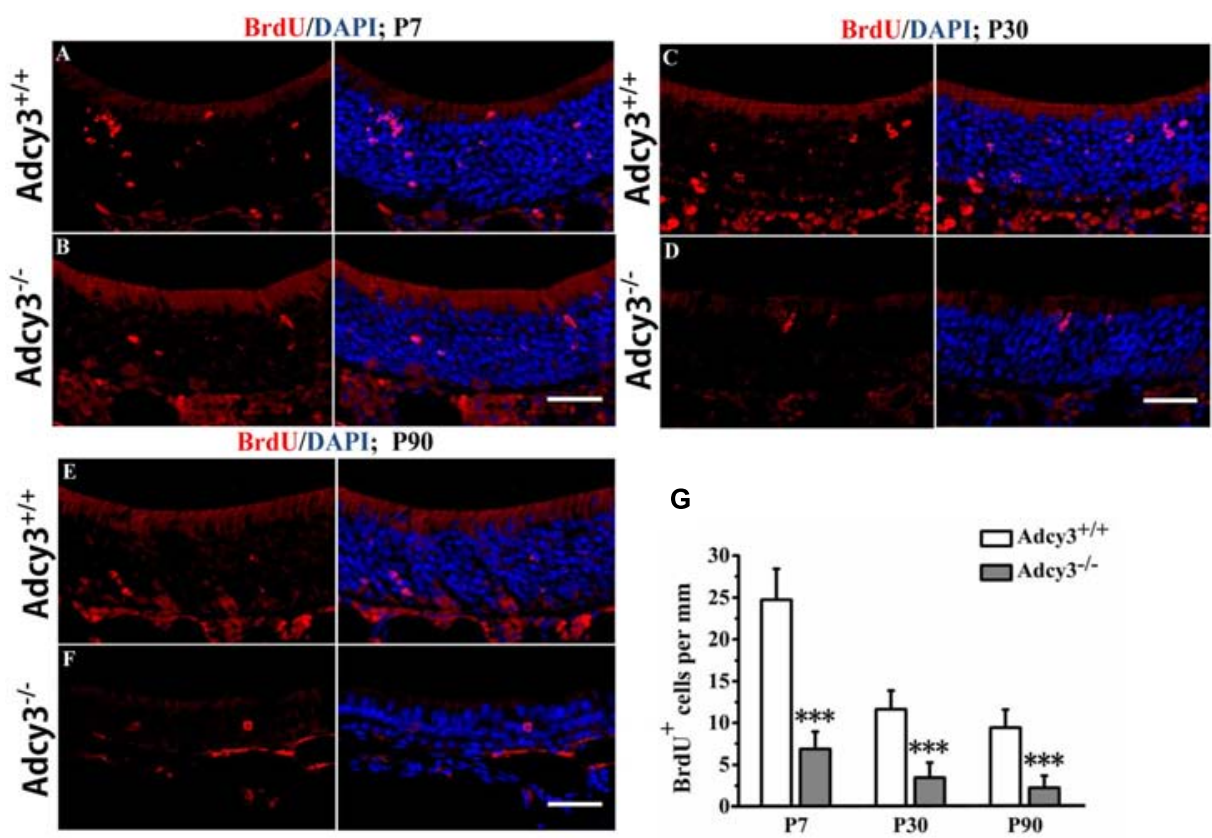

FIGURE 3 | Olfactory sensory neuron (OSN) lifespan is shortened in postnatal Adcy3-/- OSNs. (A-F) Representative images of the MOE sections stained with BrdU and nuclear DAPI (blue) in P7 (A,B), P30 (C,D), and P90 (E,F) Adcy3 $3^{+/+}$and Adcy $3^{-/-}$mice; 4 weeks post-BrdU injection. Compared with Adcy3 ${ }^{+/+}$ mice, $A d c y 3^{-/-}$mice showed significantly fewer BrdU ${ }^{+}$cells at all ages examined. (G) Quantification of $\mathrm{BrdU}^{+}$cells in the $\mathrm{MOE}$ of $\mathrm{Adcy} 3^{+/+}$and $\mathrm{Adcy} 3^{-/-}$mice 4 weeks post-BrdU injection. Data presented as mean \pm standard error; $n=3$ for each group; ${ }^{* * *} P<0.001$. Scale bars: (A-F), $40 \mu \mathrm{m}$. 

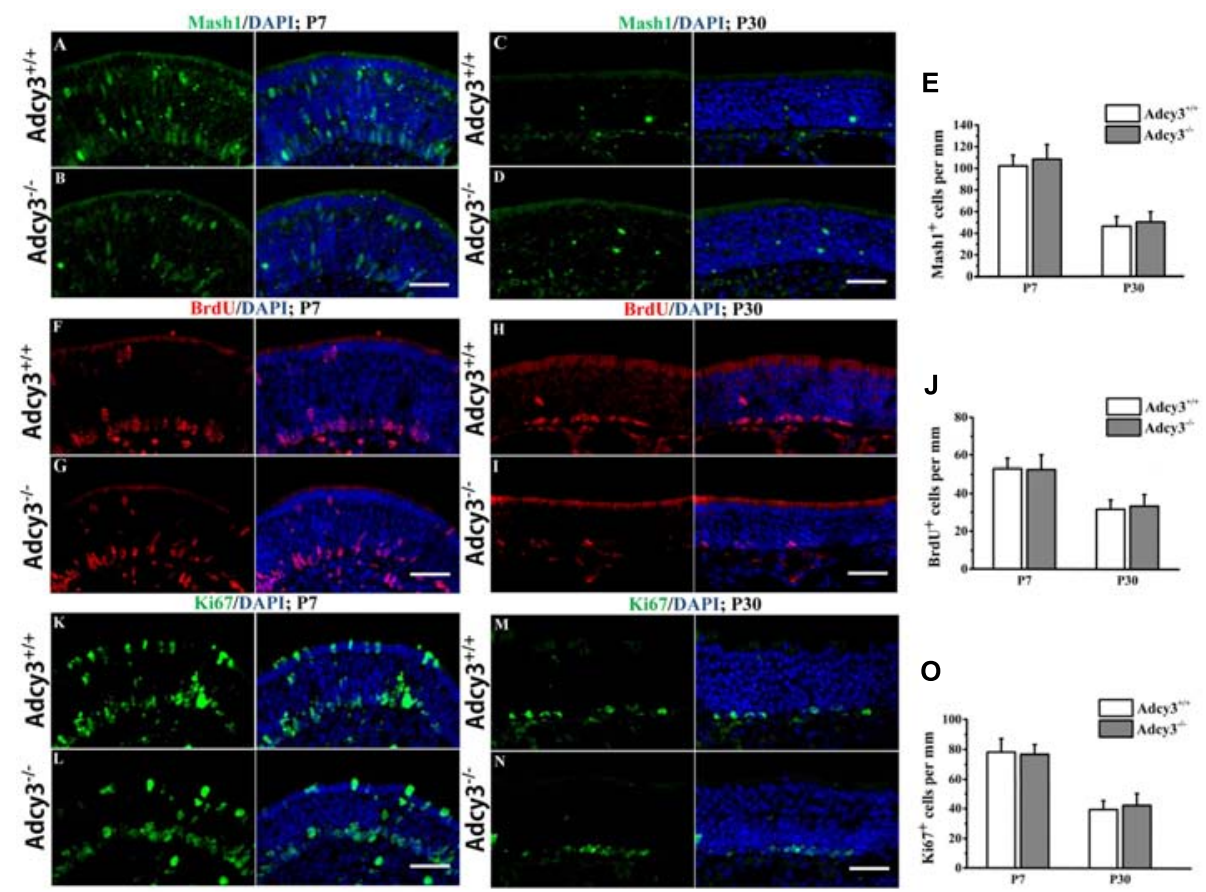

FIGURE 4 | Cell proliferation is normal in the Adcy3-/- MOE. (A-D) Representative images of MOE sections stained with Mash1 (green) and nuclear DAPI (blue) in $\mathrm{Adcy}^{+/+}$and $\mathrm{Adcy} 3^{-/-}$mice at P7 (A,B) and P30 (C,D). Mash1 ${ }^{+}$cells are expressed in the apical, intermediate, and basal regions of the MOE at P7 (A,B). Mash $1^{+}$cells are significantly reduced at P30 (C,D) in both $A d c y 3^{+/+}$and $A d c y 3^{-/-}$mice. No significant difference exists between $A d c y 3^{+/+}$and $A d c y 3^{-/-}$ mice at P7 and P30. (F-I) Representative images of MOE sections stained with BrdU and nuclear DAPI (blue) in Adcy3+/+ and Adcy3-/- mice at P7 (F,G) and P30 $\mathbf{( H , I ) . ~ M a l e ~ m i c e ~ w e r e ~ s a c r i f i c e d ~} 2 \mathrm{~h}$ after BrdU injection. We observed increased progenitors in the apical and basal positions in both $A d c y 3^{+/+}$and $A d c y 3^{-/-}$mice at P7 (F,G) and decreased at P30 (H,I). Difference was not observed between Adcy $3^{+/+}$and Adcy3 $3^{-/-}$MOE at these ages. (K-N) Representative images of MOE sections stained with $\mathrm{Ki}^{+}{ }^{+}$(another marker for cell proliferation, green) cells in the MOE of Adcy3 ${ }^{+/+}$and Adcy3 ${ }^{-/-}$mice at P7 (K,L) and P30 (M,N). Similar Ki67 expression levels were observed between $A d c y 3^{+/+}$and $A d c y 3^{-/-}$mice at the two stages. (E,J,O) Quantitative analysis of Mash $1^{+}$, BrdU $^{+}$, and Ki67 ${ }^{+}$cells in the $\mathrm{Adcy}^{+/+}$and $A d c y 3^{-/-}$MOE at P7 and P30. Data are shown as mean \pm standard error; $n=3$ for each group. Scale bars: (A-D), (F-I), and (K-N), $40 \mu \mathrm{m}$.

littermates (Figure 5G). These results demonstrate that Adcy3 deletion leads to pronounced elevation in apoptotic OSNs during MOE development.

Although the total OSN is almost the same between Adcy3 $3^{+/+}$ and $A d c y 3^{-/-}$mice at P7 and P30 (Figure 2I), the total OSN substantially decreased in $A d c y 3^{-/-}$mice at P90 (Figure 2I), and this reduction is mainly caused by the decrease in mOSN (Figure 2G,H). We performed double-staining of OMP and caspase 3 in P30 and P90 MOE to determine whether apoptosis caused the mOSN reduction in $A d c y 3^{-/-}$mice. Some OMP and caspase 3 double-labeled cells were observed in $A d c y 3^{+/+}$ mice at both P30 and P90 (Figures 6A,C,E,F). Compared with Adcy $3^{+/+}$mice, the number of double-labeled mOSN cells significantly increased in $A d c y 3^{-/-}$mice at both P30 and P90 (Figures 6B,D,E,F). These data suggest that the impairment of OSN survival may account for the decreased mOSN in Adcy3 ${ }^{-/-}$ mice.

\section{Deletion of Adcy3 Causes Loss of Olfactory Cilia and Disrupts Cilium Ultrastructure}

Olfactory cilia are essential organelles that permit the conversion of external chemical stimuli into intracellular electrical responses in OSNs (Menco, 1997). Cilia stem from each dendritic knob of OSN and run horizontally in various directions to form a meshwork with cilia from other OSNs. This intertwined mat of cilia substantially increases the sensory surface of OSNs to facilitate odorant detection. In this study, aging culminated in a marked decrease of mOSN in $A d c y 3^{-/-}$mice. To investigate whether cilia morphology was also altered by loss of mOSN after Adcy3 deletion, we performed an Ac- $\alpha$-tubulin (a ubiquitous cilium marker) immunofluorescence analysis and SEM.

Ac- $\alpha$-tubulin immunolabeling revealed a substantial decrease in immunofluorescence intensity of the ciliary layer in $A d c y 3^{-/-}$ mice at P30 and P90 (Figures 7A-F). Following SEM analysis of wild-type specimens at P7, P30, and P90, olfactory cilia were observed to be oriented parallel to the epithelial surface. The structures were also observed to run in various directions, forming a fine and dense meshwork with increasing age (Figures 7G-I). This effect occurred in parallel with an increase in mOSN number of postnatal MOE. Substantial and dense overlaps were observed in the cilia of $\mathrm{P} 90 \mathrm{Adcy} 3^{+/+}$mice (Figure 7I). In $A d c y 3^{-/-}$mice, cilia density was normal during early postnatal stages (P7, Figure 7J) but was significantly reduced at P30 and P90 (Figures 7K,L). Additionally, malformed dendritic knobs were observed in older specimens (especially 

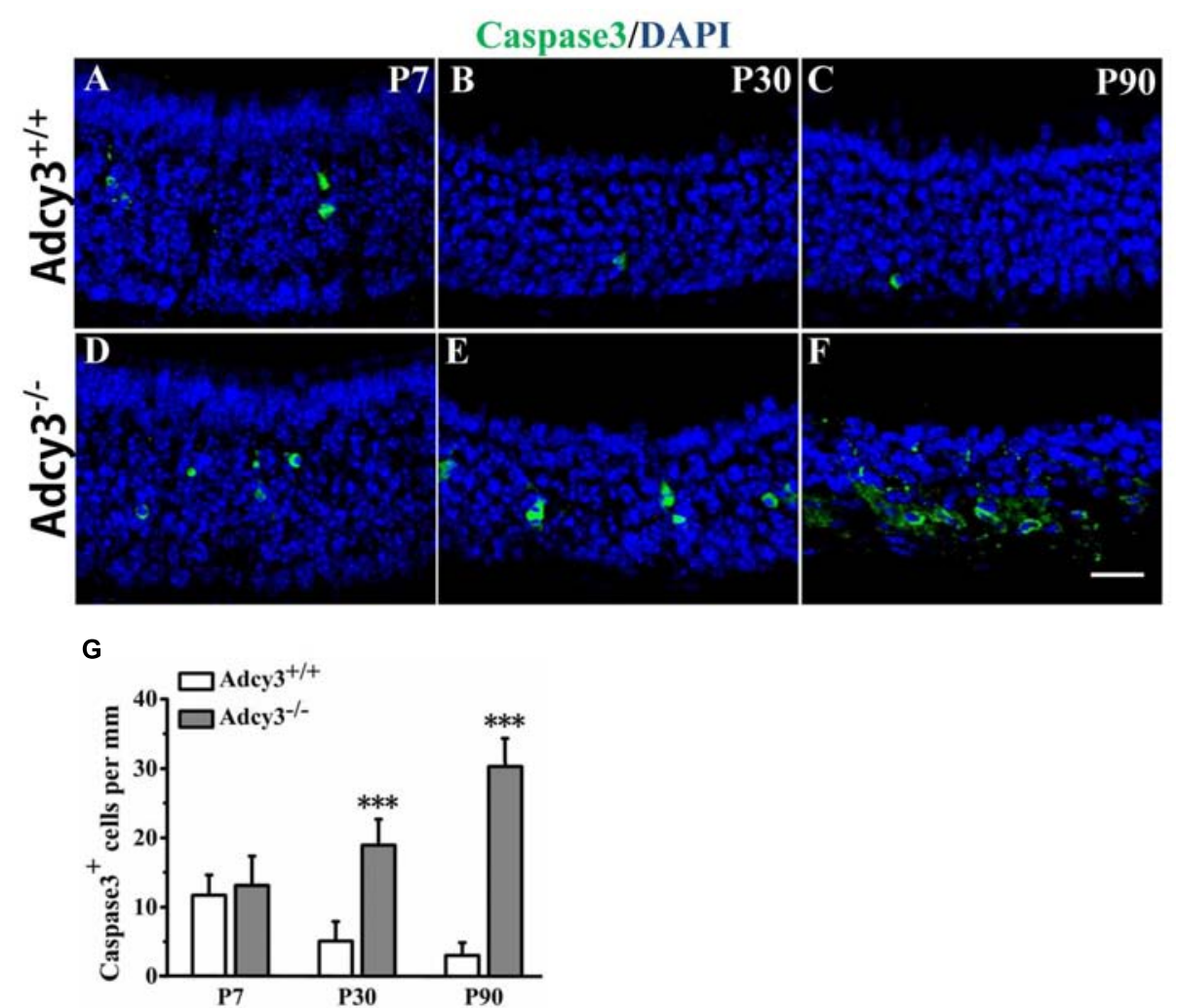

FIGURE 5 | Increased apoptosis in Adcy3-/- MOEs. (A-F) Representative images of the MOE sections stained with cleaved caspase3 (green) and nuclear DAPI (blue) in P7 (A,D), P30 (B,E), and P90 (C,F) $A d c y 3^{+/+}$and Adcy $3^{-/-}$mice. In Adcy $3^{+/+}$mice, the number of caspase ${ }^{+}$cells declined with increasing age $(\mathbf{A}, \mathbf{B}, \mathbf{C})$. Limited numbers of apoptotic cells are restricted to the basal epithelium in P30 and P90 Adcy3 $3^{+/+}$MOE (B,C). Adcy $3^{-/-}$mice at P30 and P90 displayed increased apoptotic cells in comparison with wild-type mice (E,F). (G) Quantification of caspase3 ${ }^{+}$cells in the MOE of Adcy3+/+ and Adcy3 ${ }^{-/-}$mice at P7, P30, and P90. Data are shown as mean \pm standard error; $n=3$ for each group; *** $P<0.001$. Scale bars: (A-F), $20 \mu \mathrm{m}$.

P90). Numerous $A d c y 3^{-/-}$cilia were short and stubby with enlarged knobs (Figures 7K,L, solid arrows). These results revealed that the loss of olfactory cilia occurs in conjunction with decreasing mOSNs in Adcy $3^{-/-}$mice.

Given that reduced cilium density and abnormal morphology of dendritic knobs were observed at P30 and P90 in Adcy3 $3^{-/-}$ mice, we further examined cilium ultrastructure via TEM. Ciliary microtubule configuration $(9+2$ arrangement) and dendritic knobs filled with mitochondria and numerous microtubules were observed in Adcy $3^{+/+}$mice at both P30 and P90 (Figures 8A,B,G; and 9A,B,C,H). These results were consistent with those previously observed (Jenkins et al., 2009). The membrane structures of both cilia and knobs were normal in $A d c y 3^{+/+}$mice. By contrast, the membranes displayed abnormal electron-dense outgrowths in P30 Adcy3 ${ }^{-/-}$mice (Figures 8C,D,F,H; black arrowheads). We frequently observed malformed knobs with dissolved and fractured mitochondria (Figures 8C,D, dashed arrows) and knobs lacking mitochondrial structures (Figures 8E,F). More severe ultrastructural deficiency was observed in P90 Adcy3 $3^{-/-}$mice. Many cilia and knobs had incomplete membranes (Figures 9D,F, black arrowheads, Figure 9I,J). Adcy3 $3^{-/-}$cilia were swollen (Figures 9D,F, red solid arrows), and some ciliary configurations $(9+2)$ were disordered (Figure 9J). Medullary mitochondria were detected in the knobs (Figures 9D,E, red arrowheads), indicating severe mitochondrial ultrastructure damage. We also observed "bare knobs" with no cilia (Figure 9G). This phenomenon is rarely encountered in $A d c y 3^{+/+}$mice. These findings suggest that Adcy3, which is a key ciliary membrane protein, plays a role in the maintenance of cilium ultrastructure during OSN development.

\section{DISCUSSION}

Although Adcy3 is required for odor perception (Wong et al., 2000; Wang et al., 2006) and OSN axonal projection formation (Trinh and Storm, 2003; Chesler et al., 2007; Col et al., 2007; Zou et al., 2007), its role in postnatal OSN maturation and cilium ultrastructure remains unclear. In this study, we showed that Adcy $3^{-/-}$mice exhibited cumulative disruptions in the overall structure of the MOE, OSN maturation, and cilium ultrastructure from postnatal to adult stages.

Each OSN selects an individual odor receptor gene to be expressed from a set of approximately 1200 olfactory receptor (OR) genes in a process called the OR choice. The OR choice identifies the detected odors and sends axons to particular 


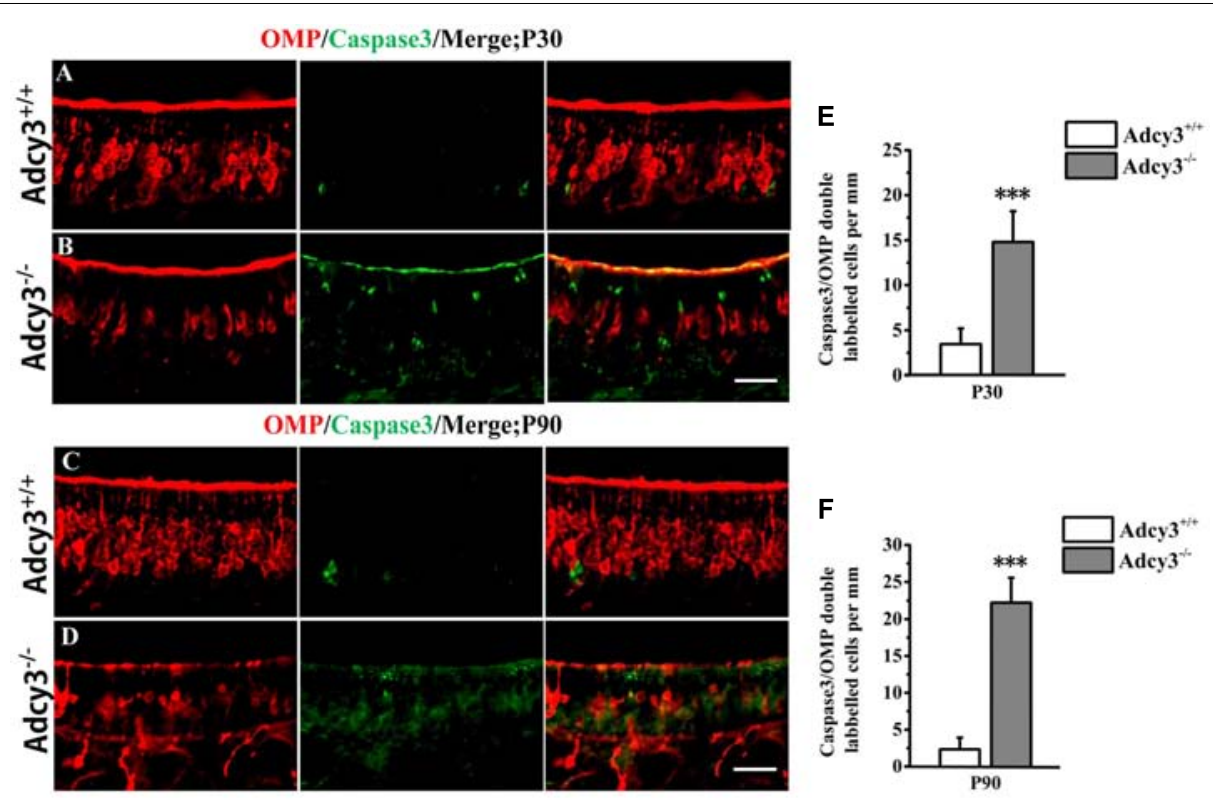

FIGURE 6 | Survival of mOSNs is impaired in Adcy $\mathbf{3}^{-/-}$MOE. (A-D) Representative images of MOE sections stained with cleaved caspase3 (green) and OMP (red) in P30 (A,B) and P90 (C,D) Adcy3 $3^{+/+}$and Adcy3 ${ }^{-/-}$mice. In Adcy3 ${ }^{+/+}$mice, some double-labeled cells were observed (A,C). At P30 and P90, Adcy3 $3^{-/-}$ mice displayed higher OMP and caspase3 double-labeled cells compared with that of wild-type mice (B,D). (E,F) Quantitative analysis of OMP and caspase3 double-labeled cells in MOE of $A d c y 3^{+/+}$and $A d c y 3^{-/-}$mice at P30 and P90. Data are shown as mean \pm standard error of mean; $n=3$ mice for each group; $* * * P<0.001$. Scale bars: (A-D), $40 \mu \mathrm{m}$.

targets in the main olfactory bulb (MOB). OR expression can be regulated by Adcy3 through a feedback loop via the downregulation of histone dimethyl enzyme LSD1; this enzyme locks in the singular choice of one allele of one OR gene (Lyons et al., 2013). Given that OR expression is a sign of OSN relative maturity, OSN differentiation is determined by OR choice and expression (Iwema and Schwob, 2003). OSNs with OR misexpression caused by disruptions in OR gene choice may be rendered uncompetitive and remain immature (Hanchate et al., 2015). This phenomenon implies the possibility that the OSN maturation retardation exhibited by the $A d c y 3^{-/-}$mice in the present study is at least, in part, a consequence of a disruption in the regulation of OR gene choice and/or expression (Lyons et al., 2013). The mechanism of OR singular expression is extremely challenging and is possibly regulated on multiple axes (Fleischmann et al., 2013). Aside from epigenetic feedback loop regulation (Lyons et al., 2013), other signal pathways may also be involved in this process. These pathways include recently identified mechanisms that are independent of canonical G-protein signaling and cAMP production (Movahedi et al., 2016). Similarly, post-selection refinement may be involved, such that a competitive relationship between OR alleles could mediate post-selection shutdown (Abdus-Saboor et al., 2016). Given that Adcy3 is temporally and spatially expressed in the subcellular locations of the cilia and axons in OSNs of MOE (Maritan et al., 2009; Challis et al., 2015; Login et al., 2015; Rodriguez-Gil et al., 2015; Scholz et al., 2016), the dynamic timing and localization of Adcy3 expression (before, during, and after OR choice) may possibly play important roles in monogenic and monoallelic OR gene expression, OSN survival, and axon targeting. For example, $A d c y 3^{-/-}$mice are anosmic because of the absence of Adcy 3 expression in dendritic cilia (Wong et al., 2000). By contrast, glycosyltransferase $\beta 3 G n T 2^{-/-}$mice are not anosmic because Adcy3 is normally trafficked to cilia (Knott et al., 2012). Both mice showed similar deficits in axon wiring and maturation impairments of OSNs because of the significantly reduced Adcy 3 expression on the axon termini-growth cone (Henion et al., 2005, 2011; Knott et al., 2012). Transgenic OR gene expression using the OMP promoter exerts minimal effect on $\mathrm{MOB}$ architecture, whereas early induction of OR expression using the G 88 promoter, which is expressed in immature OSNs, alters the projection patterns of many residual OSNs (Nguyen et al., 2010). Furthermore, even OSNs expressing an identical OR represent a non-homogeneous population (Grosmaitre et al., 2006) and can express different levels or variants of $A d c y 3$ transcripts (Col et al., 2007). Accordingly, temporal and spatial Adcy 3 conditional knockouts in mice, combined with singlecell RNAseq (Hanchate et al., 2015; Tan et al., 2015; Scholz et al., 2016) on OSNs isolated from Adcy 3 knockout versus wildtype controls, may be required to completely determine whether OSN maturation retardation in the Adcy $3^{-/-}$mice in this study resulted from a disorder in OR gene choice.

Although our data showed that mOSNs notably decreased, iOSN significantly increased in $A d c y 3^{-/-}$mice compared with their wild-type controls at all examined ages. The total OSN was not altered between $A d c y 3^{+/+}$and $A d c y 3^{-/-}$mice at P7 and P30, whereas it significantly decreased in $A d c y 3^{-/-}$mice at P90. Given that OR gene switching primarily occurs at early 


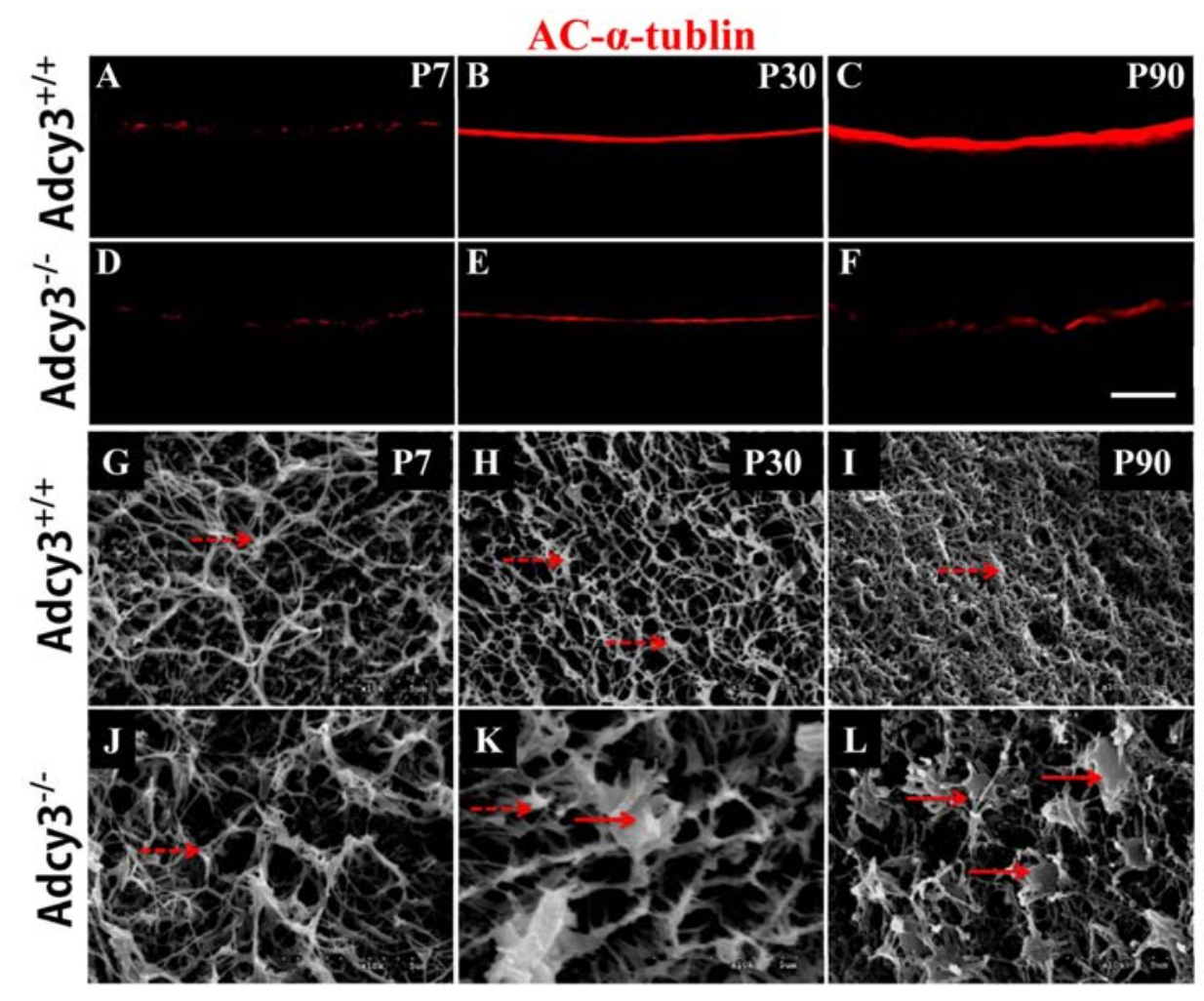

FIGURE 7 | Loss of olfactory cilia and disrupted cilium ultrastructure were observed in OSNs of Adcy $^{-/-}$mice. (A-F) Representative images of AC- $\alpha$-tubulin immunolabeling in $A d c y 3^{+/+}(\mathbf{A}-\mathbf{C})$ and $A d c y 3^{-/-}$(D-F) mice at all ages examined. In Adcy $3^{+/+}$mice, the intensity of AC- $\alpha$-tubulin-labeled ciliary layer becomes heavier with increasing age (A-C). A significant decrease in the intensity of ciliary layer is observed in P30 and P90 Adcy3-/- mice (E,F). (G-L) SEM images of $A d c y 3^{+/+}(\mathbf{G}-\mathbf{I})$ and $A d c y 3^{-/-}(\mathbf{J}-\mathbf{L})$ mice at P7, P30, and P90. Cilia run horizontally in various directions to form increasingly dense meshworks in the epithelial surface of $A d c y 3^{+/+}$mice from P7 (G) and P30 (H) until P90 (I). Adcy $3^{-/-}$mice at P30 and P90 showed significant decrease in cilium density (K,L). Both normal (dashed arrows) and abnormal dendritic knobs (solid arrows) were identified in P30 Adcy $3^{-/-}$mice (K). Moreover, the number of enlarged knobs with short and stubby cilia increased in P90 Adcy3 ${ }^{-/-}$mice (L). Scale bars: (A-F), $20 \mu \mathrm{m}$; (G-L), $5 \mu \mathrm{m}$.

developmental stages (Shykind et al., 2004), and disruption in OR gene choice may cause defects in age-independent OR expressions (Santoro and Dulac, 2012), then disruption in OR gene choice (Lyons et al., 2013) may not be the only cause of the maturation impairment of postnatal OSNs during adulthood in $A d c y 3^{-/-}$mice. Considering that OR gene choice, OSN lifespan, and OSN survival are all influenced by odorantstimulated neuronal activity and are cAMP signaling dependent (Zhao and Reed, 2001; Watt et al., 2004; Tian and Ma, 2008; Santoro and Dulac, 2012), and that OSNs of Adcy3 $3^{-/}$mice are devoid of odorant-induced activity at both behavioral and electrophysiological levels (Wong et al., 2000), then the absence of sensory input in $A d c y 3^{-/-}$mice may also account for the maturation impairment of postnatal OSNs in adult mice.

Interestingly, mice with overexpressed OAZ, the Olf/EBFassociated zinc finger protein in OSNs $\left(\mathrm{O} / \mathrm{E} 3 \mathrm{OAZ} /^{+}\right)$, demonstrated phenotypic copies of $A d c y 3^{-/-}$mice. Both mice showed pleiotropic phenotypes of decreased mOSN, increased iOSNs, axon projection defects, altered OR gene choice, and increased apoptosis (Cheng and Reed, 2007; Roby et al., 2012). Given that OAZ is an inhibitor of $\mathrm{O} / \mathrm{E}$ transcription factors preventing $\mathrm{O} / \mathrm{E}$ transcriptional target expression, and that these transcription factors have putative binding sites in the promoter region of Adcy3 gene (Robert and Tsai, 1997), these transcription molecules (Wang et al., 1993, 2012) and their repressor protein, ORZ, possibly play a role in OSN maturation through Adcy3 activation. Future studies should focus on details of mechanisms underlying OSN maturation.

In our study, the $A d c y 3^{+/+}$MOE showed an age-dependent decrease in apoptosis, with a limited number of apoptotic cells observed in the basal epithelium of adult specimens. However, the MOE of $A d c y 3^{-/-}$mice displayed high level of cell apoptosis, eventually leading to seriously atrophied and thin epithelia. Although the survival and maturation of newly generated granule cells (GCs) were shown to cause disturbance in adult $A d c y 3^{-/-}$ mice (Luo et al., 2015), MOB was suggested to promote a feedback mechanism that facilitates survival of OSNs in MOE (Schwob et al., 1992). The MOE, as the first relay station for olfactory information processing to the brain, sends information through OSN axons to the MOB. OSN neurogenesis occurs as a predominantly local phenomenon after birth in mice. Furthermore, axons arising from neurons expressing the P2 odorant receptor can still form glomerular-like loci following 

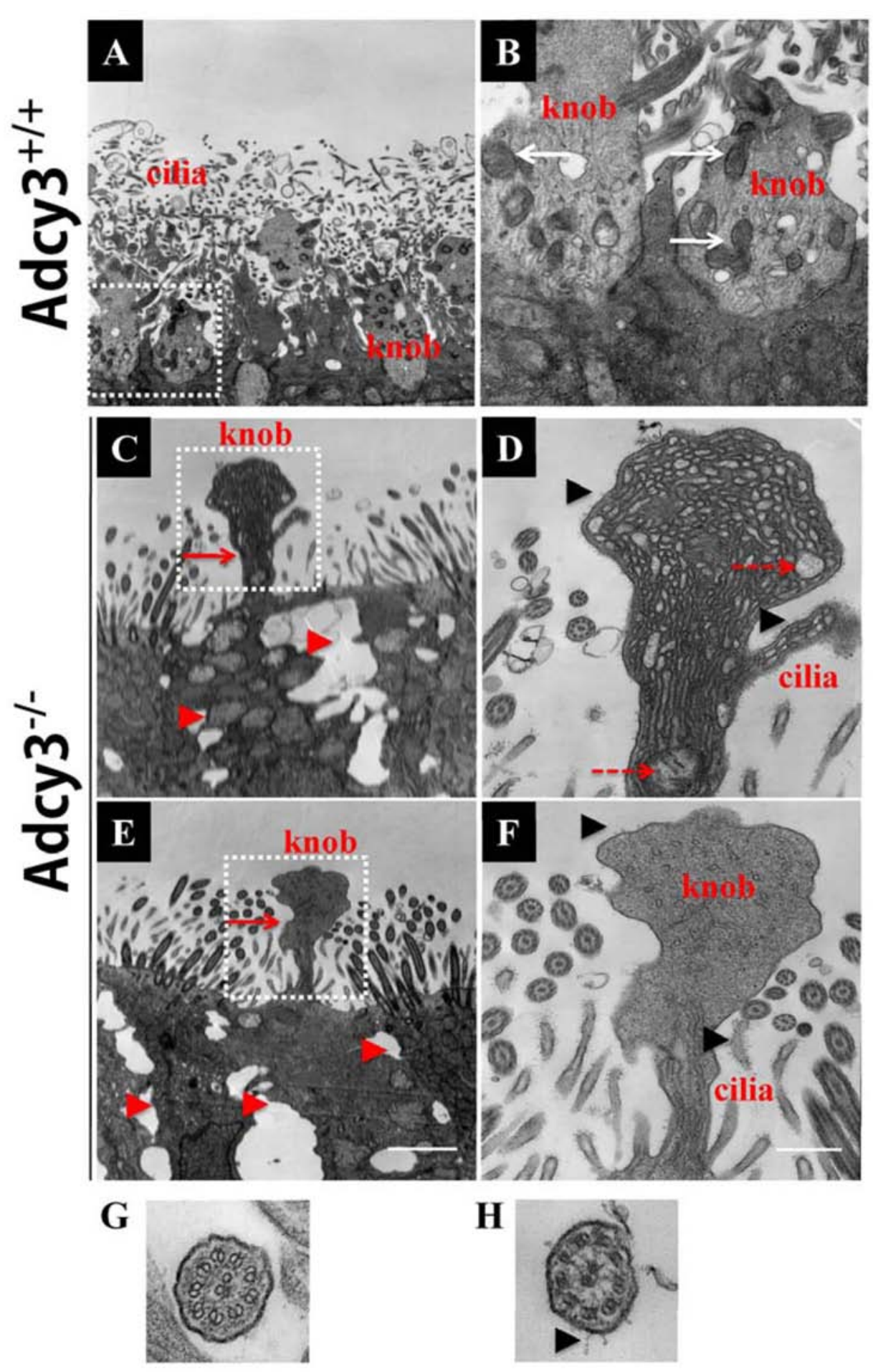

FIGURE 8 | Investigating disruption of cilium ultrastructure in P30 Adcy3-/- OSNs using TEM. (A,B,G) Cilium images in Adcy3 $3^{+/+}$mice. (C-F,H) Cilium images of $A d c y 3^{-/-}$mice. (A) Normal olfactory cilia and dendritic knobs are present in $A d c y 3^{+/+}$OSNs. (B) Increased magnification of the boxed area in (A) shows a substantial number of mitochondria (white arrows) in knobs and normal membranes (of cilia and knobs). (C,E) Malformed knobs (red arrows) and enlarged cell intervals (red arrowheads) are observed in $A d c y 3^{-/-}$OSNs. (D,F) Increased magnification of the boxed areas in (C) and (E). Membrane structure of cilia and knobs displays abnormal electron-dense areas (black arrowheads). Disrupted mitochondria is dissolved and fractured in some knobs (D, red dashed arrows). Some knobs

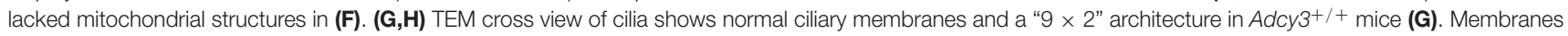
displaying an electron-dense area of mutant cilia in $A d c y 3^{-1-}$ mice (H). Scale bars: (A,C,E), $2 \mu \mathrm{m} ; \mathbf{( B , D , F ) , ~} 667 \mathrm{~nm}$; (G,H), $100 \mathrm{~nm}$. 

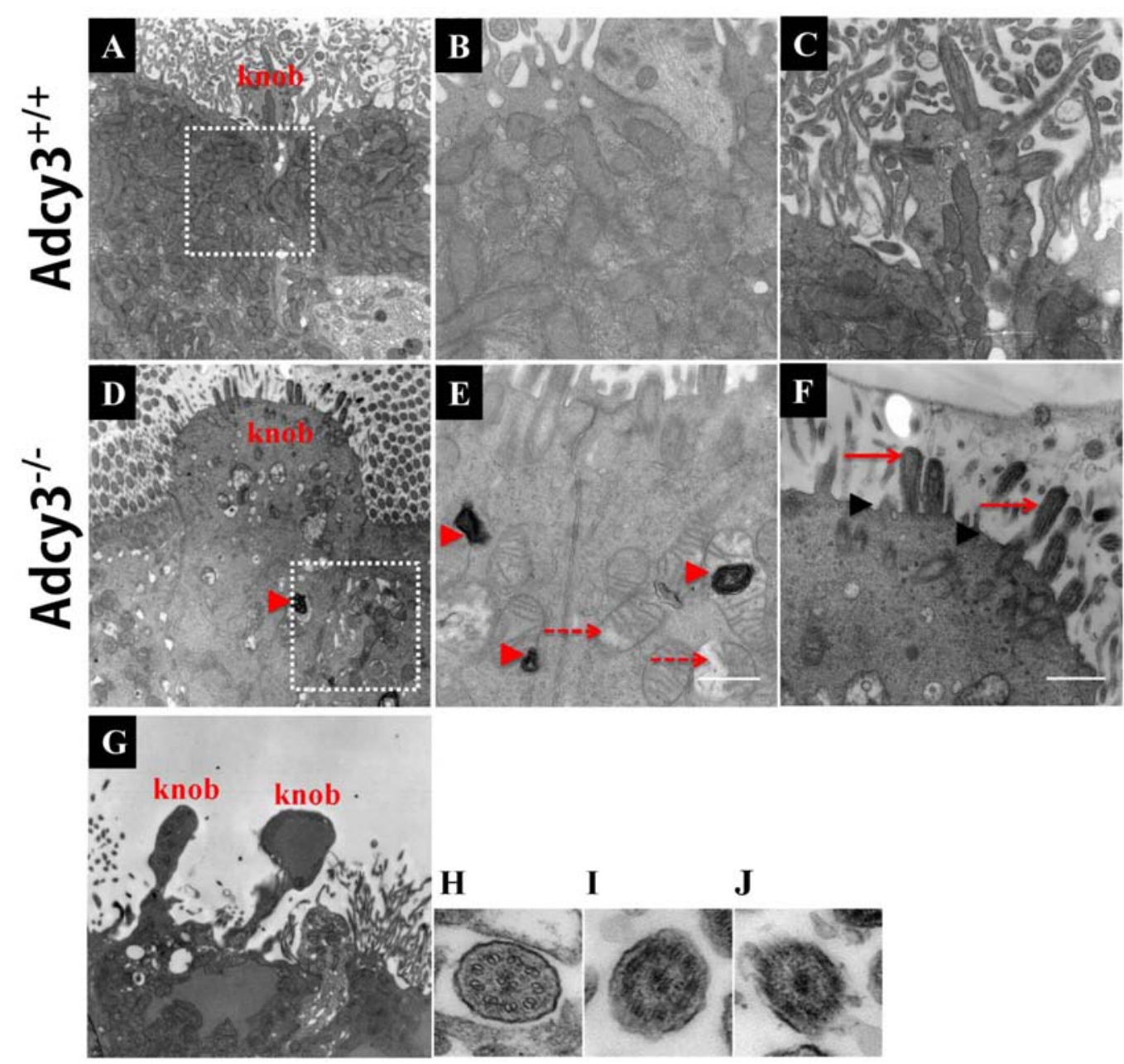

FIGURE 9 | Severely disrupted cilium ultrastructure in P90 Adcy3-/- OSNs investigated using TEM. (A-C,H) Cilium ultrastructure images of $A d c y 3^{+/+}$ mice. (D-G,I) Cilium ultrastructure images of $A d c y 3^{-/-}$mice. (A) Normal olfactory cilia and dendritic knobs were observed in $A d c y 3^{+/+}$OSNs. (B) Increased magnification of boxed area in (A) shows mitochondrial structures. (C) Increased magnification of the knob in (A) exhibits a complete membrane and numerous emanating cilia. (D) Enlarged knobs are observed in Adcy3 $3^{-/-}$OSNs. (E) Increased magnification of boxed area in (D) shows dissolved mitochondria (red dashed arrows) and medullary structures (red arrowheads). (F) Increased magnification of the knob in (D) displays an incomplete membrane structure (black arrowheads) and extensively swollen cilia (red solid arrow). (G) TEM of bare knobs in $A d c y 3^{-/-}$OSNs illustrates lacking cilia and mitochondrial structures. (H,I,J) TEM cross section view of cilia in $A d c y 3^{+/+}(\mathbf{H})$ and $A d c y 3^{-/-}$mice shows disintegrated cilium membrane (I) and disrupted ciliary "9 92 " structure (J). Scale bars: (A,D,G), 2 $\mu \mathrm{m} ;$ (B,C,E,F) $667 \mathrm{~nm} ; \mathbf{H}, \mathbf{I}, \mathbf{J}=100 \mathrm{~nm}$.

MOB removal (Bulfone et al., 1998; St John et al., 2003). In addition, regenerated olfactory axons demonstrated the capacity to form glomerular layers in the presence of an artificial biological scaffold, which is similar in size and shape to the MOB (Chehrehasa et al., 2006). Conversely, MOB development was shown to be closely associated with olfactory activity (Brunjes, 1994; Cummings and Brunjes, 1997; Petreanu and AlvarezBuylla, 2002). Accordingly, we favor the hypothesis that the $\mathrm{MOB}$, with regard to its role as mediator in processing of olfactory information from the MOE, undergoes developmental impairment in $A d c y 3^{-/-}$mice (Luo et al., 2015) as a consequence of the absence of sensory input from the OSNs (Wong et al., 2000; Wang et al., 2006), rather than a contributor to the attenuated OSN maturation of $A d c y 3^{-/-}$mice described here.
Olfactory sensory neurons in the MOE are generated by two types of basal stem cells: frequently dividing GBCs and dormant horizontal basal cells (HBCs). The possession of primary cilia is a unique characteristic of HBCs. Depletion of HBC cilia resulted in impaired regeneration of the OSNs owing to disrupted HBC proliferation (Joiner et al., 2015). Adcy3 is expressed in the primary cilia of HBCs. These data suggest that the impairment of OSN maturation observed in $A d c y 3^{-/-}$mice might be caused by HBC primary cilia dysfunction. However, our data showed that MOE-specific cell proliferation proceeded normally in Adcy $3^{-/-}$ mice. This observation rules out the possibility that disruption of OSN maturation in $A d c y 3^{-/-}$mice is a consequence of defects in primary cilia structure/function of HBCs in the MOE. 
Olfactory cilia are important organelles for OSNs in the conversion of external odor stimuli into intracellular electrical signals. Olfactory signaling cascades, which include major ORs, $\mathrm{G}_{\text {olf }}$, Adcy3, and CNG, are highly enriched in olfactory cilia (Brunet et al., 1996; Belluscio et al., 1998; Wong et al., 2000; Mombaerts, 2006). OSNs typically have short dendrites that extend apically and terminate in dendritic knobs at the epithelial surface. Cilia emanate from each knob of the OSN, with associated long and thin distal segments interacting with cilia from nearby knobs, forming a parallel meshwork. The expression patterns of cilia are positively correlated with odor perception competence. Damage to structure or function of associated cilia leads to olfactory dysfunction (Mukhopadhyay et al., 2008; Challis et al., 2015, 2016). As part of this study, we observed that the $A d c y 3^{-/-}$cilium density was not significantly different from wild-type cilium density at P7. This indicates that Adcy3 might not affect the initiation of olfactory ciliogenesis. In the MOE, olfactory ciliogenesis is initiated at around embryonic day (E) 12 (Cuschieri and Bannister, 1975). However, ciliary signaling proteins are synthesized at a later stage. For example, in rats, mRNA expression of $A d c y 3$ is first detected at E15, whereas $\mathrm{G}_{\text {olf }}$ and CNGA2 are detectable from E16 and E19, respectively (Margalit and Lancet, 1993). Accordingly, the absence of $A d c y 3$ does not obviously influence cilium patterns at early developmental stages. However, aging leads to disruption in both the density and ultrastructural morphology of the cilia in $A d c y 3^{-/-}$mice. This phenomenon included the disruption of membrane structures of OSNs, resulting in the retardation of the typical " $9+2$ " ciliary architecture and bare knobs. The cumulative disruptions that appeared in cilia were consistent with the increasing number of apoptotic mOSN in postnatal developmental of MOE after $A d c y 3$ deletion.

Centrins are classic calmodulin $\mathrm{Ca}^{2+}$-binding proteins required for basal body genesis in cilia. The ciliary density of OSNs during the early postnatal stages were normal in CETN2 mutant mice. However, massive cilia loss and disrupted structures were observed in mutant animals at P14 (and older). Impaired ciliary trafficking of olfactory signaling proteins, including Adcy3, probably caused these effects (Ying et al., 2014). Coincidentally, genetic ablation of the GOOFY gene (a Golgi protein specifically expressed in OSNs) in mice resulted in shortened olfactory cilia because of impaired intracellular trafficking of Adcy3 from the Golgi apparatus to olfactory cilia

\section{REFERENCES}

Abdus-Saboor, I., Al Nufal, M. J., Agha, M. V., Ruinart de Brimont, M., Fleischmann, A., and Shykind, B. M. (2016). An expression refinement process ensures singular odorant receptor gene choice. Curr. Biol. 26, 1083-1090. doi: 10.1016/j.cub.2016.02.039

Abercrombie, M. (1946). Estimation of nuclear population from microtome sections. Anat. Rec. 94, 239-247. doi: 10.1002/ar.1090940210

Barrios, A. W., Nunez, G., Sanchez Quinteiro, P., and Salazar, I. (2014). Anatomy, histochemistry, and immunohistochemistry of the olfactory subsystems in mice. Front. Neuroanat. 8:63. doi: 10.3389/fnana.2014.00063

Beites, C. L., Kawauchi, S., Crocker, C. E., and Calof, A. L. (2005). Identification and molecular regulation of neural stem cells in the olfactory epithelium. Exp. Cell Res. 306, 309-316. doi: 10.1016/j.yexcr.2005.03.027
(Kaneko-Goto et al., 2013). Studies performed on Caenorhabditis elegans similarly demonstrated that the cilia structures of AWB neurons could be modified by the activation of sensory signaling cascades (Mukhopadhyay et al., 2008). Taken together, these reports strongly support our finding that Adcy3 expression in olfactory cilia is required for olfactory ultrastructure maintenance in postnatal OSNs. The information increases the possibility that a feedback interaction exists between olfactory ciliary structure maintenance and proteins involved in olfactory signaling (McEwen et al., 2008). However, our present study did not resolve whether disrupted ciliary structure is sufficient to induce neuronal loss. Alternatively, disruption of ciliary structure may be a consequence of OSN degeneration. Therefore, this work is an interesting starting point for future investigation.

Taken together, our study firmly demonstrated that Adcy3 is indispensable for OSN maturation and maintenance of olfactory cilium ultrastructure from postnatal stages until adulthood in mice.

\section{AUTHOR CONTRIBUTIONS}

$\mathrm{ZZ}$, DY, and ZW conceived and designed the research; ZZ, DY, and MZ performed the experiments; DS and YZ contributed the reagents, materials, and analytic tools; ZZ, DY, NZ, and YZ analyzed the data; ZZ, DY, and ZW wrote the paper.

\section{FUNDING}

This work was supported by the National Natural Science Foundation of China (31471178 and 31171191), Natural Science Foundation of Hebei Province of China (C2016201008), Grant Project in Hebei Province of China (201235), and Post-Graduate's Innovation Fund Project of Hebei University (X2016008) (to DY).

\section{ACKNOWLEDGMENT}

We thank Jun $\mathrm{Li}$ and Haichen Lian for the routine animal husbandry and Mingshen Guo for the technical assistance on imaging.

Belluscio, L., Gold, G. H., Nemes, A., and Axel, R. (1998). Mice deficient in G(olf) are anosmic. Neuron 20, 69-81. doi: 10.1016/S0896-6273(00)80435-3

Brunet, L. J., Gold, G. H., and Ngai, J. (1996). General anosmia caused by a targeted disruption of the mouse olfactory cyclic nucleotide-gated cation channel. Neuron 17, 681-693. doi: 10.1016/S0896-6273(00)80200-7

Brunjes, P. C. (1994). Unilateral naris closure and olfactory system development. Brain Res. Brain Res. Rev. 19, 146-160. doi: 10.1016/0165-0173(94)90007-8

Bulfone, A., Wang, F., Hevner, R., Anderson, S., Cutforth, T., Chen, S., et al. (1998). An olfactory sensory map develops in the absence of normal projection neurons or GABAergic interneurons. Neuron 21, 1273-1282. doi: 10.1016/ S0896-6273(00)80647-9

Cadiou, H., Aoude, I., Tazir, B., Molinas, A., Fenech, C., Meunier, N., et al. (2014). Postnatal odorant exposure induces peripheral olfactory plasticity at the cellular level. J. Neurosci. 34, 4857-4870. doi: 10.1523/Jneurosci.0688-13.2014 
Challis, R. C., Tian, H., Yin, W., and Ma, M. (2016). Genetic ablation of type III adenylyl cyclase exerts region-specific effects on cilia architecture in the mouse nose. PLoS ONE 11:e0150638. doi: 10.1371/journal.pone.0150638

Challis, R. C., Tian, H. K., Wang, J., He, J. W., Jiang, J. B., Chen, X. M., et al. (2015). An olfactory cilia pattern in the mammalian nose ensures high sensitivity to odors. Curr. Biol. 25, 2503-2512. doi: 10.1016/j.cub.2015.07.065

Chehrehasa, F., St John, J. A., and Key, B. (2006). Implantation of a scaffold following bulbectomy induces laminar organization of regenerating olfactory axons. Brain Res. 1119, 58-64. doi: 10.1016/j.brainres.2006.08.060

Cheng, L. E., and Reed, R. R. (2007). Zfp423/OAZ participates in a developmental switch during olfactory neurogenesis. Neuron 54, 547-557. doi: 10.1016/j. neuron.2007.04.029

Chesler, A. T., Zou, D. J., Le Pichon, C. E., Peterlin, Z. A., Matthews, G. A., Pei, X., et al. (2007). A G protein/cAMP signal cascade is required for axonal convergence into olfactory glomeruli. Proc. Natl. Acad. Sci. U.S.A. 104, 10391044. doi: 10.1073/pnas.0609215104

Col, J. A., Matsuo, T., Storm, D. R., and Rodriguez, I. (2007). Adenylyl cyclasedependent axonal targeting in the olfactory system. Development 134, 24812489. doi: 10.1242/dev.006346

Coppola, D. M. (2012). Studies of olfactory system neural plasticity: the contribution of the unilateral naris occlusion technique. Neural Plast. 2012, 351752. doi: 10.1155/2012/351752

Coppola, D. M., Waguespack, A. M., Reems, M. R., Butman, M. L., and Cherry, J. A. (2006). Naris occlusion alters transductory protein immunoreactivity in olfactory epithelium. Histol. Histopathol. 21, 487-501.

Cummings, D. M., and Brunjes, P. C. (1997). The effects of variable periods of functional deprivation on olfactory bulb development in rats. Exp. Neurol. 148, 360-366. doi: 10.1006/exnr.1997.6660

Cuschieri, A., and Bannister, L. H. (1975). The development of the olfactory mucosa in the mouse: electron microscopy. J. Anat. 119, 471-498.

Farbman, A. I., Brunjes, P. C., Rentfro, L., Michas, J., and Ritz, S. (1988). The effect of unilateral naris occlusion on cell dynamics in the developing rat olfactory epithelium. J. Neurosci. 8, 3290-3295.

Fleischmann, A., Abdus-Saboor, I., Sayed, A., and Shykind, B. (2013). Functional interrogation of an odorant receptor locus reveals multiple axes of transcriptional regulation. PLoS Biol. 11:e1001568. doi: 10.1371/journal.pbio. 1001568

Grosmaitre, X., Vassalli, A., Mombaerts, P., Shepherd, G. M., and Ma, M. (2006). Odorant responses of olfactory sensory neurons expressing the odorant receptor MOR23: a patch clamp analysis in gene-targeted mice. Proc. Natl. Acad. Sci. U.S.A. 103, 1970-1975. doi: 10.1073/pnas.05084 91103

Hagglund, M., Berghard, A., Strotmann, J., and Bohm, S. (2006). Retinoic acid receptor-dependent survival of olfactory sensory neurons in postnatal and adult mice. J. Neurosci. 26, 3281-3291. doi: 10.1523/JNEUROSCI.4955-05.2006

Hanchate, N. K., Kondoh, K., Lu, Z., Kuang, D., Ye, X., Qiu, X., et al. (2015). Single-cell transcriptomics reveals receptor transformations during olfactory neurogenesis. Science 350, 1251-1255. doi: 10.1126/science.aad2456

Henion, T. R., Faden, A. A., Knott, T. K., and Schwarting, G. A. (2011). beta3GnT2 maintains adenylyl cyclase-3 signaling and axon guidance molecule expression in the olfactory epithelium. J. Neurosci. 31, 6576-6586. doi: 10.1523/ JNEUROSCI.0224-11.2011

Henion, T. R., Raitcheva, D., Grosholz, R., Biellmann, F., Skarnes, W. C., Hennet, T., et al. (2005). Beta1,3-N-acetylglucosaminyltransferase 1 glycosylation is required for axon pathfinding by olfactory sensory neurons. J. Neurosci. 25, 1894-1903. doi: 10.1523/JNEUROSCI.4654-04.2005

Heron, P. M., Stromberg, A. J., Breheny, P., and McClintock, T. S. (2013). Molecular events in the cell types of the olfactory epithelium during adult neurogenesis. Mol. Brain 6:49. doi: 10.1186/1756-6606-6-49

Iwema, C. L., and Schwob, J. E. (2003). Odorant receptor expression as a function of neuronal maturity in the adult rodent olfactory system. J. Comp. Neurol. 459, 209-222. doi: 10.1002/cne.10583

Jang, W., Chen, X., Flis, D., Harris, M., and Schwob, J. E. (2014). Label-retaining, quiescent globose basal cells are found in the olfactory epithelium. J. Comp. Neurol. 522, 731-749. doi: 10.1002/cne.23470

Jenkins, P. M., McEwen, D. P., and Martens, J. R. (2009). Olfactory cilia: linking sensory cilia function and human disease. Chem. Senses 34, 451-464. doi: 10. 1093/chemse/bjp020
Joiner, A. M., Green, W. W., McIntyre, J. C., Allen, B. L., Schwob, J. E., and Martens, J. R. (2015). Primary cilia on horizontal basal cells regulate regeneration of the olfactory epithelium. J. Neurosci. 35, 13761-13772. doi: 10.1523/JNEUROSCI. 1708-15.2015

Kaneko-Goto, T., Sato, Y., Katada, S., Kinameri, E., Yoshihara, S., Nishiyori, A., et al. (2013). Goofy coordinates the acuity of olfactory signaling. J. Neurosci. 33, 12987-U12681. doi: 10.1523/Jneurosci.4948-12.2013

Kikuta, S., Sakamoto, T., Nagayama, S., Kanaya, K., Kinoshita, M., Kondo, K., et al. (2015). Sensory deprivation disrupts homeostatic regeneration of newly generated olfactory sensory neurons after injury in adult mice. J. Neurosci. 35, 2657-2673. doi: 10.1523/Jneurosci.248414.2015

Kim, S. Y., Mammen, A., Yoo, S. J., Cho, B., Kim, E. K., Park, J. I., et al. (2015). Phosphoinositide and Erk signaling pathways mediate activity-driven rodent olfactory sensory neuronal survival and stress mitigation. J. Neurochem. 134, 486-498. doi: 10.1111/jnc.13131

Knott, T. K., Madany, P. A., Faden, A. A., Xu, M., Strotmann, J., Henion, T. R., et al. (2012). Olfactory discrimination largely persists in mice with defects in odorant receptor expression and axon guidance. Neural Dev. 7:17. doi: 10.1186/17498104-7-17

Kondo, K., Suzukawa, K., Sakamoto, T., Watanabe, K., Kanaya, K., Ushio, M., et al. (2010). Age-related changes in cell dynamics of the postnatal mouse olfactory neuroepithelium: cell proliferation, neuronal differentiation, and cell death. J. Comp. Neurol. 518, 1962-1975. doi: 10.1002/cne. 22316

Livak, K. J., and Schmittgen, T. D. (2001). Analysis of relative gene expression data using real-time quantitative PCR and the 2(-Delta Delta C(T)) Method. Methods 25, 402-408. doi: 10.1006/meth.2001.1262

Login, H., Haglin, S., Berghard, A., and Bohm, S. (2015). The stimulus-dependent gradient of Cyp26B1 $(+)$ olfactory sensory neurons is necessary for the functional integrity of the olfactory sensory map. J. Neurosci. 35, 13807-13818. doi: 10.1523/Jneurosci.2247-15.2015

Luo, J., Chen, X., Pan, Y. W., Lu, S., Xia, Z., and Storm, D. R. (2015). The type 3 adenylyl cyclase is required for the survival and maturation of newly generated granule cells in the olfactory bulb. PLoS ONE 10:e0122057. doi: 10.1371/journal. pone.0122057

Lyons, D. B., Allen, W. E., Goh, T., Tsai, L., Barnea, G., and Lomvardas, S. (2013). An epigenetic trap stabilizes singular olfactory receptor expression. Cell 154, 325-336. doi: 10.1016/j.cell.2013.06.039

Mahalik, T. J. (1996). Apparent apoptotic cell death in the olfactory epithelium of adult rodents: death occurs at different developmental stages. J. Comp. Neurol. 372, 457-464. doi: 10.1002/(SICI)1096-9861(19960826)372:3<457:: AID-CNE8 > 3.3.CO;2-F

Margalit, T., and Lancet, D. (1993). Expression of olfactory receptor and transduction genes during rat development. Brain Res. Dev. Brain Res. 73, 7-16. doi: 10.1016/0165-3806(93)90040-H

Maritan, M., Monaco, G., Zamparo, I., Zaccolo, M., Pozzan, T., and Lodovichi, C. (2009). Odorant receptors at the growth cone are coupled to localized cAMP and Ca2+ increases. Proc. Natl. Acad. Sci. U.S.A. 106, 3537-3542. doi: 10.1073/ pnas.0813224106

McEwen, D. R., Jenkins, P. M., and Martens, J. R. (2008). Olfactory cilia: our direct neuronal connection to the external world. Curr. Top. Dev. Biol. 85, 333-370. doi: 10.1016/S0070-2153(08)00812-0

Menco, B. P. (1997). Ultrastructural aspects of olfactory signaling. Chem. Senses 22, 295-311. doi: 10.1093/chemse/22.3.295

Mombaerts, P. (2006). Axonal wiring in the mouse olfactory system. Annu. Rev. Cell Dev. Biol. 22, 713-737. doi: 10.1146/annurev.cellbio.21.012804.093915

Movahedi, K., Grosmaitre, X., and Feinstein, P. (2016). Odorant receptors can mediate axonal identity and gene choice via cAMP-independent mechanisms. Open Biol. 6:160018. doi: 10.1098/rsob.160018

Mukhopadhyay, S., Lu, Y., Shaham, S., and Sengupta, P. (2008). Sensory signalingdependent remodeling of olfactory cilia architecture in C. elegans. Dev. Cell 14, 762-774. doi: 10.1016/j.devcel.2008.03.002

Nguyen, M. Q., Marks, C. A., Belluscio, L., and Ryba, N. J. (2010). Early expression of odorant receptors distorts the olfactory circuitry. J. Neurosci. 30, 9271-9279. doi: 10.1523/JNEUROSCI.1502-10.2010

Petreanu, L., and Alvarez-Buylla, A. (2002). Maturation and death of adult-born olfactory bulb granule neurons: role of olfaction. J. Neurosci. 22, 6106-6113. 
Robert, Y. L., and Tsai, R. R. R. (1997). Cloning and functional characterization of roaz, a zinc finger protein that interacts with $\mathrm{O} / \mathrm{E}-1$ to regulate gene expression: implications for olfactory neuronal development. J. Neurosci. 17, 4159-4169.

Roby, Y. A., Bushey, M. A., Cheng, L. E., Kulaga, H. M., Lee, S. J., and Reed, R. R. (2012). Zfp423/OAZ mutation reveals the importance of Olf/EBF transcription activity in olfactory neuronal maturation. J. Neurosci. 32, 13679-13688. doi: 10.1523/JNEUROSCI.6190-11.2012

Rodriguez-Gil, D. J., Bartel, D. L., Jaspers, A. W., Mobley, A. S., Imamura, F., and Greer, C. A. (2015). Odorant receptors regulate the final glomerular coalescence of olfactory sensory neuron axons. Proc. Natl. Acad. Sci. U.S.A. 112, 5821-5826. doi: 10.1073 /pnas.1417955112

Santoro, S. W., and Dulac, C. (2012). The activity-dependent histone variant H2BE modulates the life span of olfactory neurons. Elife 1:e00070. doi: 10.7554/eLife. 00070

Scholz, P., Kalbe, B., Jansen, F., Altmueller, J., Becker, C., Mohrhardt, J., et al. (2016). Transcriptome analysis of murine olfactory sensory neurons during development using single cell RNA-Seq. Chem. Senses 41, 313-323. doi: 10. 1093/chemse/bjw003

Schwob, J. E., Szumowski, K. E., and Stasky, A. A. (1992). Olfactory sensory neurons are trophically dependent on the olfactory bulb for their prolonged survival. J. Neurosci. 12, 3896-3919.

Sciacovelli, M., Goncalves, E., Johnson, T. I., Zecchini, V. R., da Costa, A. S., Gaude, E., et al. (2016). Fumarate is an epigenetic modifier that elicits epithelialto-mesenchymal transition. Nature 537, 544-547. doi: 10.1038/nature19353

Shykind, B. M., Rohani, S. C., O’Donnell, S., Nemes, A., Mendelsohn, M., Sun, Y., et al. (2004). Gene switching and the stability of odorant receptor gene choice. Cell 117, 801-815. doi: 10.1016/j.cell.2004.05.015

St John, J. A., Clarris, H. J., McKeown, S., Royal, S., and Key, B. (2003). Sorting and convergence of primary olfactory axons are independent of the olfactory bulb. J. Comp. Neurol. 464, 131-140. doi: 10.1002/cne.10777

Stahl, B., Distel, H., and Hudson, R. (1990). Effects of reversible nare occlusion on the development of the olfactory epithelium in the rabbit nasal septum. Cell Tissue Res. 259, 275-281. doi: 10.1007/BF00318449

Tan, L., Li, Q., and Xie, X. S. (2015). Olfactory sensory neurons transiently express multiple olfactory receptors during development. Mol. Syst Biol. 11:844. doi: $10.15252 / \mathrm{msb} .20156639$

Tian, H., and Ma, M. (2008). Activity plays a role in eliminating olfactory sensory neurons expressing multiple odorant receptors in the mouse septal organ. Mol. Cell. Neurosci. 38, 484-488. doi: 10.1016/j.mcn.2008.04.006

Trinh, K., and Storm, D. R. (2003). Vomeronasal organ detects odorants in absence of signaling through main olfactory epithelium. Nat. Neurosci. 6, 519-525. doi: $10.1038 / \mathrm{nn} 1039$

Wang, M. M., Tsai, R. Y., Schrader, K. A., and Reed, R. R. (1993). Genes encoding components of the olfactory signal transduction cascade contain a DNA binding site that may direct neuronal expression. Mol. Cell. Biol. 13, 5805-5813. doi: 10.1128/MCB.13.9.5805

Wang, S. Z., Ou, J. H., Zhu, L. H. J., and Green, M. R. (2012). Transcription factor ATF5 is required for terminal differentiation and survival of olfactory sensory neurons. Proc. Natl. Acad. Sci. U.S.A. 109, 18589-18594. doi: 10.1073/pnas. 1210479109

Wang, Z., Phan, T., and Storm, D. R. (2011). The type 3 adenylyl cyclase is required for novel object learning and extinction of contextual memory: role of cAMP signaling in primary cilia. J. Neurosci. 31, 5557-5561. doi: 10.1523/JNEUROSCI. 6561- 10.2011

Wang, Z., Sindreu, C. B., Li, V., Nudelman, A., Chan, G. C.-K., and Storm, D. R. (2006). Pheromone detection in male mice depends on signaling through the type 3 adenylyl cyclase in the main olfactory epithelium. J. Neurosci. 26, 7375-7379. doi: 10.1523/Jneurosci.1967-06.2006

Wang, Z., and Storm, D. R. (2006). Extraction of DNA from mouse tails. Biotechniques 41, 410-412. doi: 10.2144/000112255

Watt, W. C., Sakano, H., Lee, Z. Y., Reusch, J. E., Trinh, K., and Storm, D. R. (2004). Odorant stimulation enhances survival of olfactory sensory neurons via MAPK and CREB. Neuron 41, 955-967. doi: 10.1016/S0896-6273(04) 00075-3

Weiler, E., and Farbman, A. I. (1997). Proliferation in the rat olfactory epithelium: age-dependent changes. J. Neurosci. 17, 3610-3622.

Wong, S. T., Trinh, K., Hacker, B., Chan, G. C., Lowe, G., Gaggar, A., et al. (2000). Disruption of the type III adenylyl cyclase gene leads to peripheral and behavioral anosmia in transgenic mice. Neuron 27, 487-497. doi: 10.1016/ S0896-6273(00)00060-X

Ying, G. X., Avasthi, P., Irwin, M., Gerstner, C. D., Frederick, J. M., Lucero, M. T., et al. (2014). Centrin 2 is required for mouse olfactory ciliary trafficking and development of ependymal cilia planar polarity. J. Neurosci. 34, 6377-6388. doi: 10.1523/Jneurosci.0067-14.2014

Zhao, H., and Reed, R. R. (2001). X inactivation of the OCNC1 channel gene reveals a role for activity-dependent competition in the olfactory system. Cell 104, 651-660. doi: 10.1016/S0092-8674(01)00262-8

Zhao, S., Tian, H., Ma, L., Yuan, Y., Yu, C. R., and Ma, M. (2013). Activity-dependent modulation of odorant receptor gene expression in the mouse olfactory epithelium. PLoS ONE 8:e69862. doi: 10.1371/journal.pone. 0069862

Zou, D. J., Chesler, A. T., Le Pichon, C. E., Kuznetsov, A., Pei, X., Hwang, E. L., et al. (2007). Absence of adenylyl cyclase 3 perturbs peripheral olfactory projections in mice. J. Neurosci. 27, 6675-6683. doi: 10.1523/Jneurosci.0699-07.2007

Conflict of Interest Statement: The authors declare that the research was conducted in the absence of any commercial or financial relationships that could be construed as a potential conflict of interest.

Copyright (c) 2017 Zhang, Yang, Zhang, Zhu, Zhou, Storm and Wang. This is an open-access article distributed under the terms of the Creative Commons Attribution License (CC BY). The use, distribution or reproduction in other forums is permitted, provided the original author(s) or licensor are credited and that the original publication in this journal is cited, in accordance with accepted academic practice. No use, distribution or reproduction is permitted which does not comply with these terms. 